\title{
Rainfall Mechanisms for One of the Wettest Tropical Cyclones on Record in Australia-Oswald (2013)
}

\author{
Difei Deng And Elizabeth A. Ritchie \\ School of Science, University of New South Wales, Canberra, Australian Capital Territory, Australia
}

(Manuscript received 27 May 2019, in final form 4 April 2020)

\begin{abstract}
Tropical Cyclone Oswald (2013) is considered to be one of the highest-impact storms to make landfall in northern Australia even though it only reached a maximum category 1 intensity on the Australian category scale. After making landfall on the west coast of Cape York Peninsula, Oswald turned southward, and persisted for more than 7 days moving parallel to the coastline as far south as $30^{\circ} \mathrm{S}$. As one of the wettest tropical cyclones (TCs) in Australian history, the favorable configurations of a lower-latitude active monsoon trough and two consecutive midlatitude trough-jet systems generally contributed to the maintenance of the Oswald circulation over land and prolonged rainfall. As a result, Oswald produced widespread heavy rainfall along the east coast with three maximum centers near Weipa, Townsville, and Rockhampton, respectively. Using high-resolution WRF simulations, the mechanisms associated with TC Oswald's rainfall are analyzed. The results show that the rainfall involved different rainfall mechanisms at each stage. The land-sea surface friction contrast, the vertical wind shear, and monsoon trough were mostly responsible for the intensity and location for the first heavy rainfall center on the Cape York Peninsula. The second torrential rainfall near Townsville was primarily a result of the local topography and land-sea frictional convergence in a conditionally unstable monsoonal environment with frictional convergence due to TC motion modulating some offshore rainfall. The third rainfall area was largely dominated by persistent high vertical wind shear forcing, favorable large-scale quasigeostrophic dynamic lifting from two midlatitude trough-jet systems, and mesoscale frontogenesis lifting.
\end{abstract}

\section{Introduction}

At landfall, tropical cyclones (TCs) pose significant forecast problems because of the potential devastation to life and property from strong winds and heavy rain (Rappaport 2000; Chen 2012). Forecasting precipitation in landfalling TCs is a complicated problem as rainfall is influenced by many factors including the land-sea surface contrast, local topography, frictionally induced boundary layer convergence caused by TC translation, environmental vertical wind shear (VWS) and interactions between the TC and multiscale environmental factors (e.g., Klein et al. 2000; Ritchie and Elsberry 2001; Rogers et al. 2003; Atallah et al. 2007). Consequently, precipitation can vary greatly from storm to storm and even at different times for the same storm after it has made landfall (Lonfat et al. 2004). Because of these factors, the rainfall associated with the landfall of TCs continues

Corresponding author: Difei Deng, ddfttkl@gmail.com to be one of the most challenging and important forecast problems and needs further investigation.

Some early studies indicated that the coastal rainfall associated with TCs is mainly caused by the wind weakening over land due to the higher drag coefficient of the land surface compared to the ocean and enhanced lower-level convergence on the onshore side at landfall (e.g., Miller 1958). This surface friction convergence on the onshore side of the TC is dominated by tangential deceleration at the top of the planetary boundary layer (Li et al. 2014). During landfall, topography cannot only affect the TC track but also modulate TC rainfall. Rainfall tends to be enhanced on the windward side of mountainous terrain because the moist air converges and ascends. Extreme rainfall can occur when a TC circulation approaches and moves over mountainous areas because of the accretion of cloud water, or the release of buoyant motions triggered by upslope flow, and enhanced topographic lifting (Lin et al. 2001; Wu et al. 2002; Misumi 1996; Rotunno and Ferretti 2001, 2003; Smith et al. 2009a; Yu and Cheng 2008; DeHart and Houze 2017). 
In addition to the local land-sea contrast and topographic effects, studies emphasize the importance of TC motion in TC rainfall asymmetries. Several studies demonstrated that the asymmetric boundary friction induced by a moving vortex could enhance lower-level convergence ahead of the TC relative to its motion. Shapiro (1983) used an ideal boundary layer model to show that for slow-moving storms the convergence was concentrated in the front quadrant, while for fasting-moving storms it was located more directly in the front to frontright quadrants in the Northern Hemisphere. Corbosiero and Molinari (2003) provided a detailed review of the effect of storm motion on TC structure and rainfall. They found that the asymmetry in precipitation occurred preferentially in the front quadrants of the inner core and inner band regions and was shifted to the right of the track in the outer core and at larger radii. Chen et al. (2006) and Deng and Ritchie (2018) have also shown that the TC motion may become dominant in controlling TC rainfall asymmetry in a low-shear environment.

TCs normally weaken, and the rainfall correspondingly decreases during and after making landfall. However, sometimes TCs reintensify after landfall or asymmetric rainfall enhancement can occur in the remnants of the TC due to both external environmental influences and internal dynamics (Bao et al. 2015; Deng et al. 2017). For example, when a TC is impacted by environmental VWS a wavenumber- 1 asymmetry in the inner-core temperature, vertical velocity, and corresponding precipitation field, similar to the balanced vortex response to VWS demonstrated by DeMaria et al. (1993) and Jones (1995), is usually observed and simulated in the TC circulation (e.g., Frank and Ritchie 1999, 2001). The precipitation varies azimuthally with respect to the shear vector (Reasor et al. 2013; Hence and Houze 2011; DeHart et al. 2014; Didlake and Kumjian 2017). Convection is initially produced in the downshear right (left) quadrant and is then advected cyclonically to the left (right) of the shear vector in the Northern (Southern) Hemisphere in response to VWS (Corbosiero and Molinari 2002; Braun et al. 2006; Halverson et al. 2006). Another key environmental interaction is a favorable TC-trough interaction (Hanley et al. 2001) when an approaching trough enhances relative eddy flux convergence of angular momentum in the TC outflow layer (Molinari and Vollaro 1989, 1990), which leads to enhanced upper-level TC outflow providing a greater coverage of quasigeostrophic forcing for ascent (McTaggart-Cowan et al. 2013; Fischer et al. 2017). While the strong VWS associated with a passing trough can have a detrimental effect on TC intensity, in the case of a favorable trough interaction, the balanced vortex response to the trough forcing leads to enhanced upper-level outflow and evacuation of mass from the TC core, which lowers the TC central pressure and increases the low-level winds (DeMaria et al. 1993; Kaplan and DeMaria 2003; Leroux et al. 2013; Peirano et al. 2016). In addition, a wavenumber- 1 asymmetry in the rainfall pattern associated with the TC during a TCtrough interaction will occur due to both the effect of the associated VWS on the TC structure as well as the enhancement of rainfall in the trough-jet-TC outflow region (e.g., Ritchie and Elsberry 2001, 2003). Other atmospheric environmental conditions that contribute to the rainfall changes associated with landfalling TCs include low-level moisture transport, low-level frontogenesis, and atmospheric instability (Wang et al. 2009; Moore et al. 2013; Milrad et al. 2013; Riemer and Laliberté 2015).

In January of 2013, TC Oswald caused severe flooding along the Australian east coast lasting for more than 7 days while over land. The high-impact TC formed in the monsoon trough over the Gulf of Carpentaria and reached a maximum category 1 intensity when it made landfall on the western side of Cape York Peninsula on 21 January 2013 (black track in Fig. 1). It weakened after landfall and was downgraded to a tropical low on 22 January. The remnant circulation turned southward and moved parallel to the coastline as far south as Tamworth $\left(31^{\circ} \mathrm{S}\right)$. Although its circulation was over land, Oswald slightly intensified as it moved southward on 23-24 January. Followed by a slowdown on 2526 January when moving across Rockhampton, Oswald accelerated southward and dissipated on 29 January. Oswald caused widespread extreme rainfall, catastrophic flooding, high winds, storm surge and tornadoes in the eastern coastal region during its passage southward (Bureau of Meteorology 2013, Special climate statement 44$)$. Three heavy rain regions were directly associated with Oswald (Fig. 2a). The first rain region (I) occurred near the west coast of Cape York Peninsula, where Weipa station recorded $328 \mathrm{~mm}$ in $24 \mathrm{~h}$. The second rain area (II) mainly occurred in the topographically favored region near Cairns and Townsville, with maximum rainfall just over $500 \mathrm{~mm}$. The third heavy rainfall region (III) extended southward, with large areas of accumulated rainfall exceeding $200 \mathrm{~mm}$ per day. The most significant rainfall was in the Rockhampton area during the third heavy rainfall process, where the rainfall amount exceeded $700 \mathrm{~mm}$ at several stations. Seven people died and thousands of people were evacuated. Key infrastructure including houses, bridges, transport links, and communication was damaged and destroyed in this region. Across the affected region, damage from severe weather and flooding amounted to over $\$ 2.5$ billion (U.S. dollars).

The motivation of the paper is to analyze the highimpact weather event, investigate the mechanisms for 
(a) Track

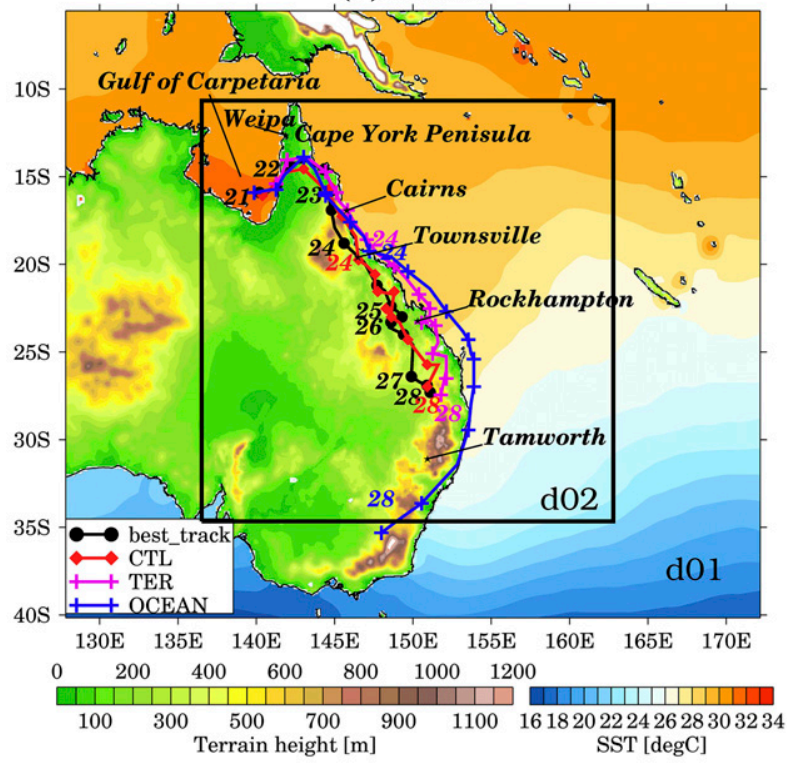

(b) Intensity

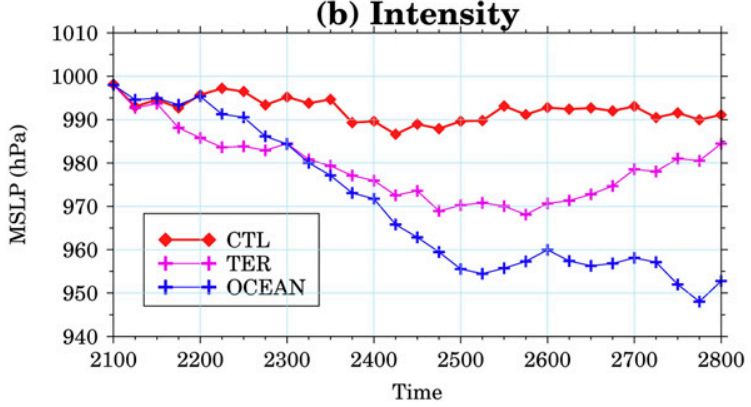

FIG. 1. (a) The best track from the BoM (black line, 0000 UTC positions provided) and the WRF simulated tracks; and (b) time series of central minimum pressure from the CTL (red line), TER (magenta line), and OCEAN (blue line) simulations for TC Oswald (2013). The topography (unit: $\mathrm{m}$ ) and SST (unit: ${ }^{\circ} \mathrm{C}$ ) are overlaid in (a).

the three heavy rainfall regions affected by Oswald and study how a weak TC can produce such destructive impacts in order to increase understanding of how TCrelated rainfall might affect Australia and other similar locations globally. The paper will be organized as follows. Section 2 describes the data and methodology. Section 3 presents the synoptic conditions associated with TC Oswald's landfall, turn to the south, and extended track, as well as TC vortex structural characteristics. The rainfall mechanisms at the three locations associated with Oswald are analyzed in section 4. Discussion and conclusions are presented in the last section.

\section{Data and methodology}

\section{a. Data}

The observed gridded daily rainfall data are obtained from the Bureau of Meteorology (BoM) archive at http://www.bom.gov.au/jsp/awap/rain/index.jsp. The TC Oswald best track can be downloaded from the "Database of past tropical cyclone tracks" under the given link at http://www.bom.gov.au/cyclone/history/index.shtml. The global 6-hourly, $1^{\circ} \times 1^{\circ}$ horizontal grid spacing final analysis gridded datasets (FNL) provided by the National Centers for Environmental Prediction (https://rda.ucar.edu/ datasets/ds083.2/) are used as initial and boundary conditions for the numerical model.

\section{b. Experiment design}

The Weather Research and Forecasting (WRF) Model, version 3.7.1 (Skamarock et al. 2008), was used to simulate TC Oswald (2013). The model control simulation (CTL) was set up with two nested domains, D01 and D02 centered at $24^{\circ} \mathrm{S}, 150^{\circ} \mathrm{E}$ with horizontal resolution of 18 and $2 \mathrm{~km}$, respectively, and 61 vertical layers (Fig. 1a). The model was initialized at 0000 UTC 21 January 2013 and run for $168 \mathrm{~h}$. The physics parameterizations used for the simulation are as follows: the Kain-Fritsch cumulus parameterization only for D01 (Kain 2004), WRF doublemoment 6-class microphysics scheme (Hong et al. 2004), RRTMG longwave and shortwave radiation schemes (Mlawer et al. 1997), and the Yonsei University planetary boundary layer scheme (Hong et al. 2004, 2006). 3D spectral nudging was used on both domains for the first $48 \mathrm{~h}$ of the simulation on low wavenumbers (Deng et al. 2004; Deng and Stauffer 2006; Glisan et al. 2013) to prevent the synoptic environment from drifting from the FNL analyses during the longer simulation period (Otte et al. 2012). It is a technique used for regional climate simulations. While the synoptic-scale flow (low wavenumbers) remains true to the analyses, the mesoscale flow and major rainfall processes and mechanisms analyzed from the inner grid is not affected by the technique.

Because there were several possible rainfall mechanisms responsible for the heavy rainfall, two sensitivity simulations were also run to help determine the main external forcing for each of the three heavy rainfall periods during Oswald's passage. For the first sensitivity simulation, the height of the terrain was halved to help isolate the effects of terrain on the heavy rainfall (TER). The second sensitivity simulation was run over the ocean only with all land removed from the model grids (OCEAN) to better determine the possible impact of the land-sea contrast. The sea surface temperatures were interpolated across the removed land surface and the 3D spectral nudging was also used above the boundary layer for the first $48 \mathrm{~h}$ of the simulation to control the synoptic environment.

\section{c. Validation of the control simulation}

Figure 1 shows the best track (black line) for TC Oswald from the BoM and the WRF control simulation 


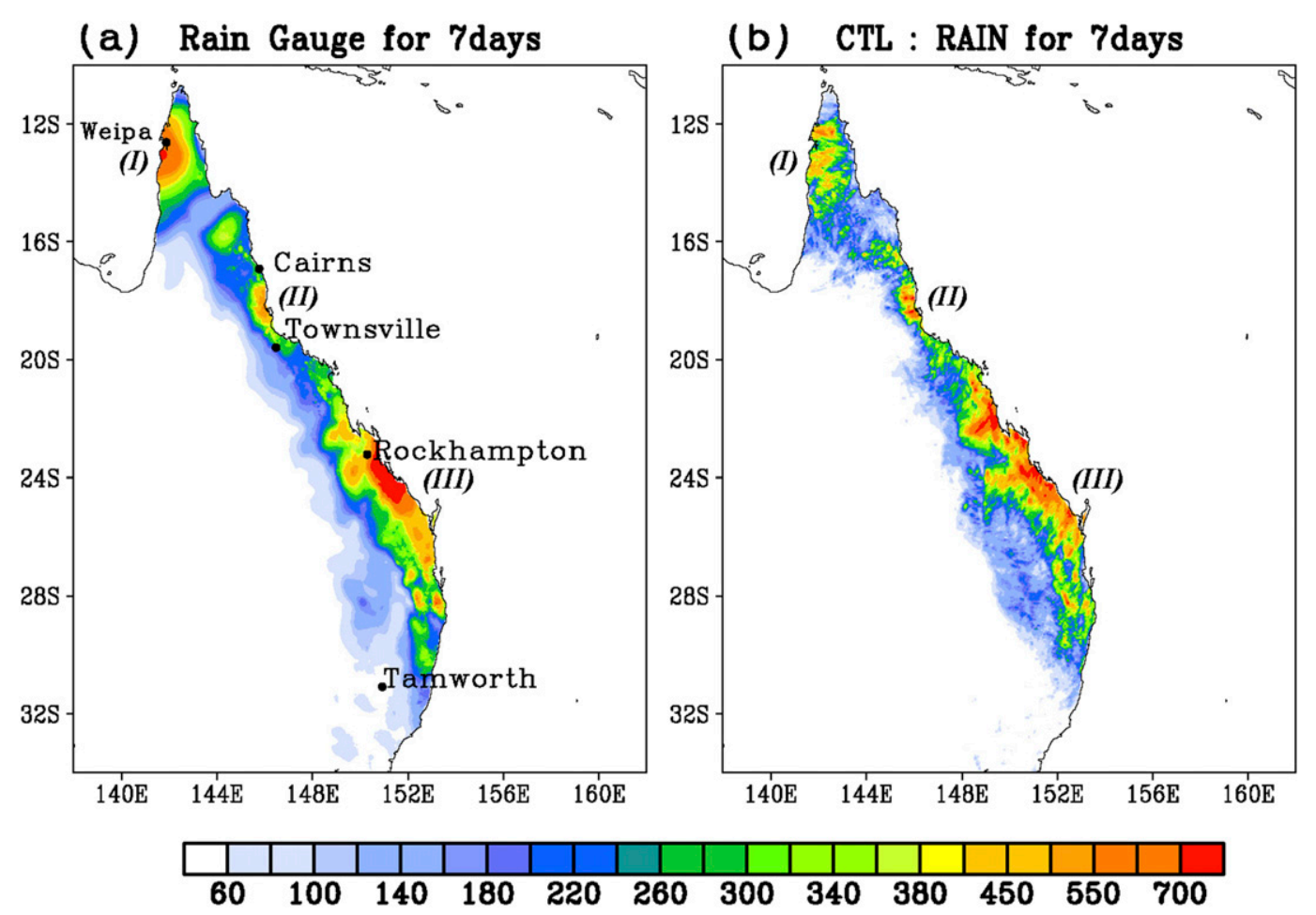

FIG. 2. The 7-day accumulated rainfall (unit: $\mathrm{mm}$ ) from 0000 UTC 21 Jan to 0000 UTC 28 Jan 2013 using: (a) rain gauges and (b) CTL.

track (CTL, red line) from 0000 UTC 21 January to 0000 UTC 28 January 2013. The simulated track is generally in good agreement with the observed track, including the north to southward bend after making landfall, and the translation speed. Before making landfall, both the simulated and the observed TC moved northward. Soon after landfall on 22 January, Oswald turned southeastward with a translation speed of approximately $4-6 \mathrm{~m} \mathrm{~s}^{-1}$ along the east coast. There is no minimum sea level pressure (MSLP) or surface maximum wind speed recorded in the BoM best track archives after 0000 UTC 22 January 2013 since the maximum wind speed had decreased below $25 \mathrm{kt}\left(1 \mathrm{kt} \approx 0.51 \mathrm{~m} \mathrm{~s}^{-1}\right)$. However, from the BoM report on TC Oswald, two intensifying periods were observed and reported (http://www.bom.gov.au/cyclone/history/ tracks/index.shtml). The first was from 21 to 22 January approximately 1 day prior to making landfall over the western Cape York Peninsula. The central pressure dropped $5 \mathrm{hPa}$ from 996 to $991 \mathrm{hPa}$. The other period of intensification was from 23 to 24 January when Oswald passed Cairns and Townsville while still over land. During this period, the central pressure decreased slightly to $988 \mathrm{hPa}$. The CTL simulation (red line) appears to capture these two slight intensification periods (Fig. 1b). Subsequently, the Oswald circulation maintained through the end of the simulation.
Figure 2 shows a comparison between the observed and simulated 7-day accumulated rainfall from CTL associated with Oswald along the east coast. Both panels demonstrate that there are three maximum rainfall regions exceeding $500 \mathrm{~mm}$ at Weipa, Townsville, and the elongated rainfall region near Rockhampton, respectively. Both the accumulated (Fig. 2) and daily simulated rainfall (not shown) matches closely with the observed rain gauge analysis, including rainswath location, rain amount and timing during this period. This successful CTL simulation is used to analyze the environmental fields and diagnose TC structure and the rainfall mechanisms in the study.

Compared with CTL, there were no apparent differences in the TC tracks in the two sensitivity experiments prior to 23 January (Fig. 1a magenta and blue lines) due to the spectral nudging. After this time, the TER track (magenta line) shifts slightly to the east of the CTL track, and the OCEAN track (blue line) shifts farther east. The intensity trends in the two sensitivity simulations are much stronger than the CTL intensity throughout the 7 days primarily due to the reduced topographic elevation and longer time over the ocean in the TER simulation and the reduced land surface friction in the OCEAN simulation. The simulated TC reached its peak on 24-25 January, with the minimum 
MSLP of $955 \mathrm{hPa}$ in OCEAN, followed by $970 \mathrm{hPa}$ in TER and $987 \mathrm{hPa}$ in CTL. Moreover, the comparison between the two sensitivity experiments shows that the TER TC intensity was initially stronger than that in OCEAN for the first 2 days of the simulation from 1200 UTC 21 January to 0000 UTC 23 January but was weaker thereafter. This intensity difference is because after replacing the land surface with ocean, there was more moisture available in the TC near-environment compared to that in TER. As a result of this higher environmental moisture, a broader outer rainband developed in OCEAN initially with relatively slower development in the inner core during the initial 2 days of simulation compared with TER (not shown). Due to the rapid development and expansion of the outer rainband in OCEAN, the boundary layer inflow into the inner core was blocked, resulting in a slower intensification in the TC inner core in OCEAN. A more detailed dynamical explanation can be found in the idealized simulations in Wang (2009) and Stovern and Ritchie (2016). Once the eyewall became well organized in OCEAN after 0000 UTC 23 January, there was a more rapid increase in OCEAN intensity than in TER. After 26 January, the TC intensity in the two sensitivity simulations diverged, weakening in TER and reintensifying in OCEAN. Compared to CTL and OCEAN, the vortex weakened in TER more rapidly probably because the vortex center moved back from the ocean surface to the land surface in the final stage of simulation. The accumulated rainfall swaths in TER and OCEAN generally resemble CTL, presented in an elongated northwest-southeast-oriented pattern, though some details vary (not shown). These differences will be analyzed in detail in section 4 .

\section{Synoptic background and vortex structural characteristics}

Figure 3 depicts the evolution of the mid- to upperlevel and lower-level atmospheric conditions during TC Oswald's passage from CTL. Three representative times are shown: 1) prior to landfall (Figs. 3a,d); 2) initial interaction with a midlatitude system (Figs. 3b,e); and 3) the extended track (Figs. 3c,f). Oswald was initially embedded in the west-east-oriented tropical monsoon trough (denoted by MT in Fig. 3d) within a large reservoir of moisture on 21 January [Bureau of Meteorology (2013), Special climate statement 44]. Consequently, the total rainfall distribution exhibited a west-east-oriented band during this period. In addition, the monsoon was active between 19 and 25 January 2013, just prior to and during the arrival of Oswald, which provided favorable low-level vorticity and high environmental moisture (http://poama.bom.gov.au/project/ s2s/monsoon/aus_monsoon_active_days.ascii). The rainfall centers I and II occurred in this large-scale monsoon trough between 21 and 23 January. On 24 January (Figs. 3b,e), as Oswald moved southward, the midlatitude meridional circulation amplified. An upper-level midlatitude trough approached Oswald from the southwest, with a strengthening jet ahead of the trough. In the lower troposphere, the tropical oceanic moisture connected with the Oswald circulation (Fig. 3e). After a short intermittent period, a second midlatitude trough approached Oswald and by 27 January (Fig. 3c), Oswald had become increasingly embedded into the midlatitude trough. Figure $3 \mathrm{f}$ also highlights how the tropical moisture moved southward with Oswald. This abundant moisture contributed to the persistent and widespread rainfall III and flooding along the east coast during the impact of two consecutive troughs. Oswald was finally trapped by, and dissipated into, the second midlatitude trough on 29 January.

The environmental VWS near Oswald generally increased during the 7 days as Oswald moved southward toward the midlatitudes (Fig. 4a). The VWS was generally weak prior to 23 January with a maximum on 22 January. After this time, the VWS increased considerably. Two periods of high VWS occurred from 23 to 25 January and 27 to 28 January as a result of the increasing mid- to upper-level northwesterly winds when the consecutive upper-level troughs, passed to the south of Oswald (Fig. 4b). In addition, Fig. 4c shows the time-height section of average radial wind (shaded) and tangential wind (solid lines). Three cyclonic tangential wind maxima are apparent at $800 \mathrm{hPa}$, on 21 January when TC Oswald was embedded within the monsoon trough before making landfall, from 23 to 25 January during the passage of the first trough, and after 27 January during the passage of the second trough, respectively, corresponding to the three minimum MSLP values in CTL in Fig. 1b. These maxima in tangential wind were associated with increased low-level radial inflow and upper-level radial outflow. Note that during the passage of the two midlatitude troughs, the upper-level radial outflow extended downward to $600 \mathrm{hPa}$ (red shaded in Fig. 4c), and the cyclonic tangential wind weakened and changed sign in the upper levels (dashed line in Fig. 4c), with a minimum value of $-2 \mathrm{~m} \mathrm{~s}^{-1}$ from 24 to 25 January and after 27 January at $150 \mathrm{hPa}$. The extension downward of the upper-level outflow and the increase of anticyclonic circulation suggest a decrease in inertial stability, which provides favorable conditions for a TC-trough (jet) interaction (Davidson and Kar 2002). By late 27 January, the cyclonic tangential wind decreased throughout the troposphere 
(a)

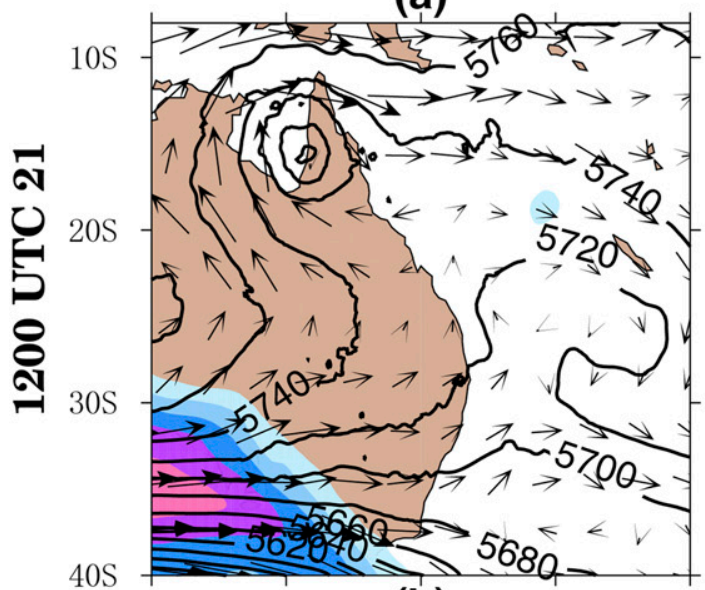

(b)

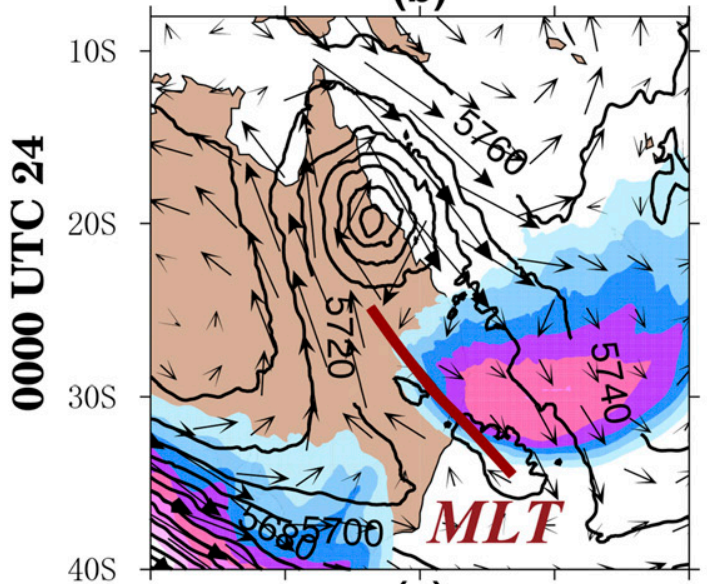

(c)

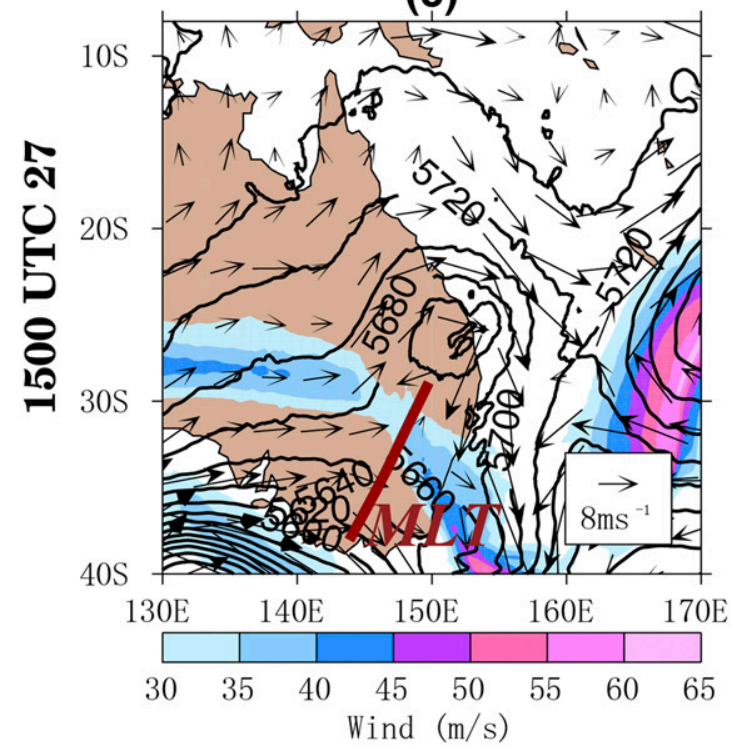

(d)

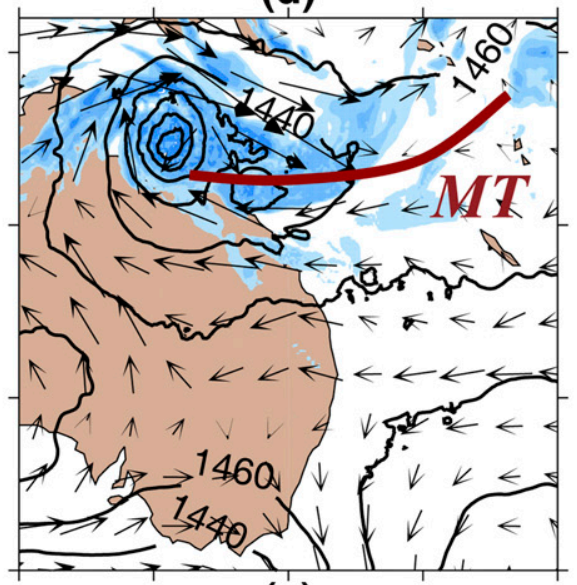

(e)

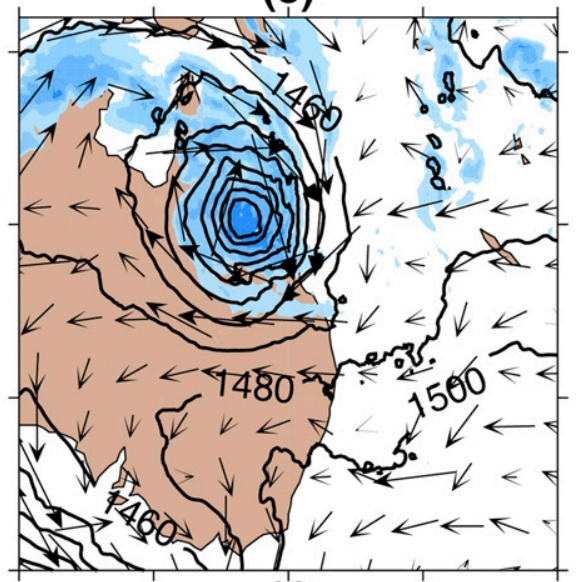

(f)

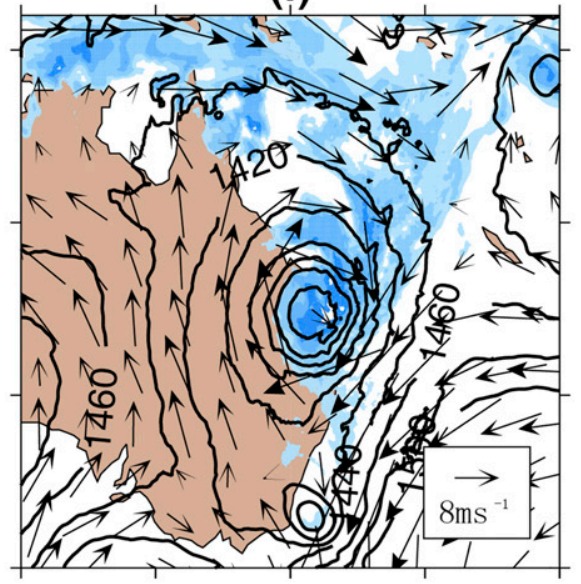

$130 \mathrm{E} \quad 140 \mathrm{E} \quad 150 \mathrm{E} \quad 160 \mathrm{E} \quad 170 \mathrm{E}$

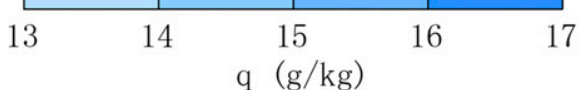

FIG. 3. (a)-(c) 200-hPa horizontal wind speed (shaded: $\geq 20 \mathrm{~m} \mathrm{~s}^{-1}$ ), and 500-hPa horizontal wind vectors and geopotential height (black contour, intervals: $20 \mathrm{dam}$ ); (d)-(f) 850-hPa horizontal wind vector, geopotential height (black contour, intervals: 20 dam), and specific humidity (shaded, unit: $\mathrm{g} \mathrm{kg}^{-1}$ ) at (a),(d) $1200 \mathrm{UTC} 21 \mathrm{Jan}$ (b),(e) 0000 UTC 24 Jan; and (c),(f) 1500 UTC 27 Jan 2013 in CTL. The thick brown line denotes the axis of the monsoon trough (MT) in (d) and midlatitude trough (MLT) in (b),(c). 
(a)

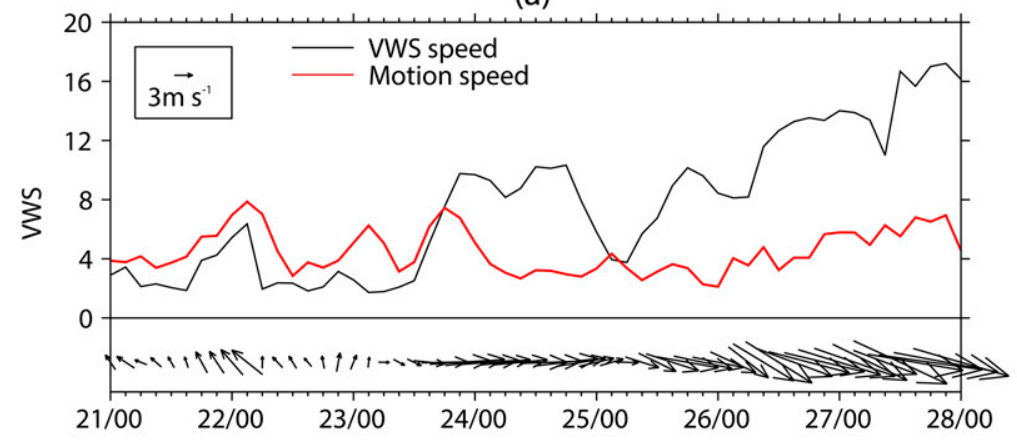

(b)

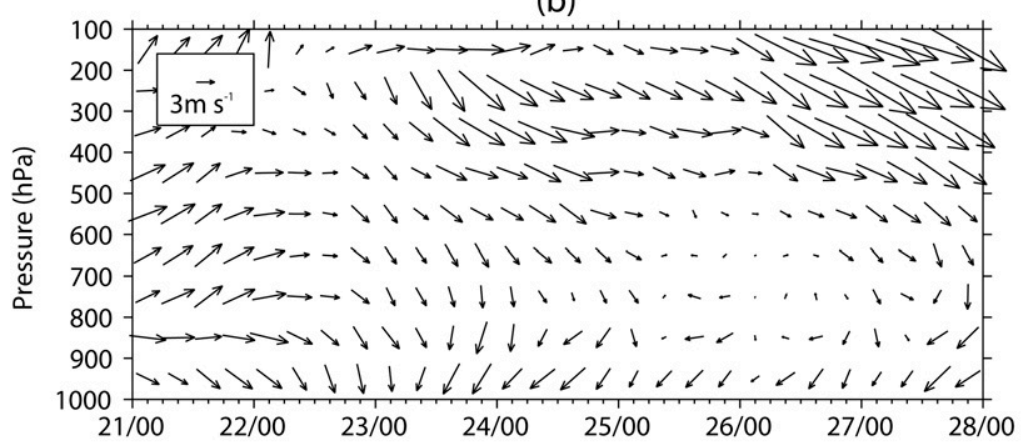

(c)

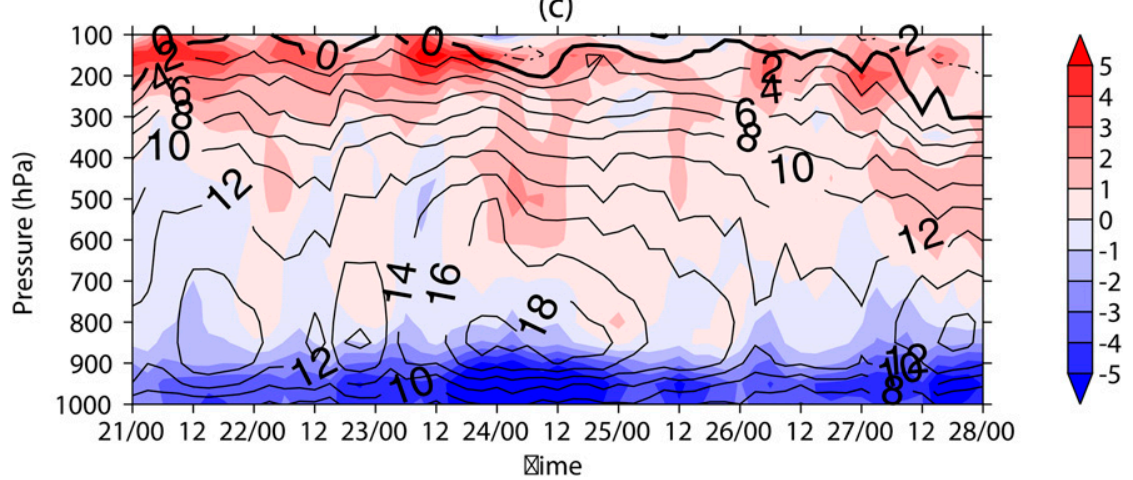

FIG. 4. Time series for the Oswald CTL simulation of: (a) 200-850-hPa environmental vertical wind shear averaged in a $200-800-\mathrm{km}$ annulus (vector indicates shear direction, unit: $\mathrm{m} \mathrm{s}^{-1}$ ) and TC motion speed (unit: $\mathrm{m} \mathrm{s}^{-1}$ ), (b) time-height cross section of the average wind, and (c) mean tangential wind (black contour, unit: $-1 \times \mathrm{m} \mathrm{s}^{-1}$ ) and radial wind (shaded) within a $500-\mathrm{km}$ radius.

except below $600 \mathrm{hPa}$ when Oswald dissipated in the second midlatitude trough.

From the analysis of the large-scale background and TC wind structure, the weakened Oswald circulation lasted for approximately 7 days over land, moving from a tropical environment (i.e., monsoon trough) into the midlatitudes (i.e., westerly trough and upperlevel jet), and produced widespread heavy rainfall and flooding, which made it one of the wettest TCs in Australian history. What are the physical processes associated with such heavy rainfall? What are the rainfall mechanisms especially for the three rainfall maximum centers along the east coast of Australia? In the following section we will address these questions.

\section{The rainfall mechanisms associated with Oswald}

Figure 5 presents the time-compass section of 3hourly accumulated rainfall averaged within $500 \mathrm{~km}$ of the TC center from the CTL simulation. During the 7 days, Oswald evolved from a more symmetric rainfall pattern prior to 23 January to an extremely asymmetric 

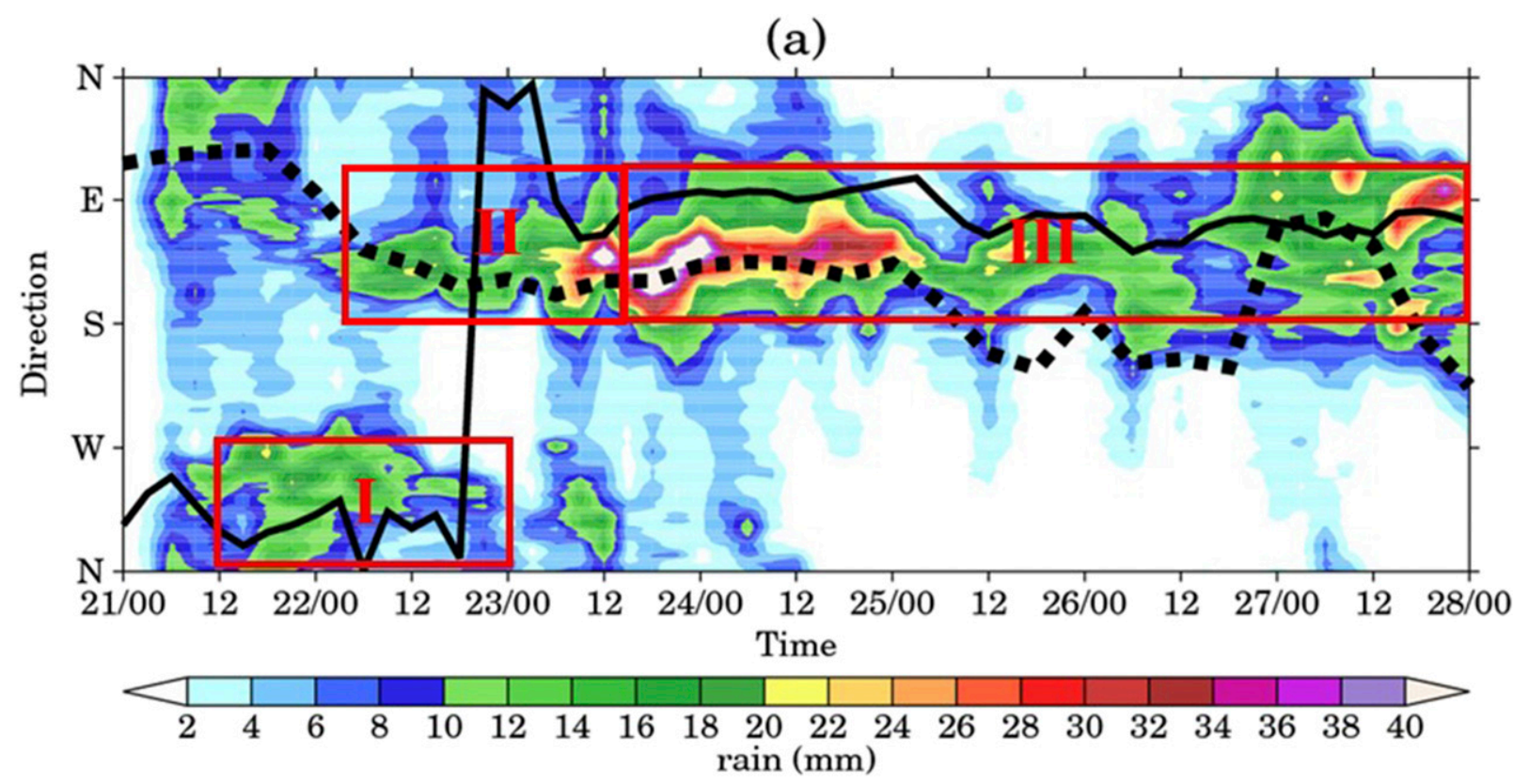

(b) I

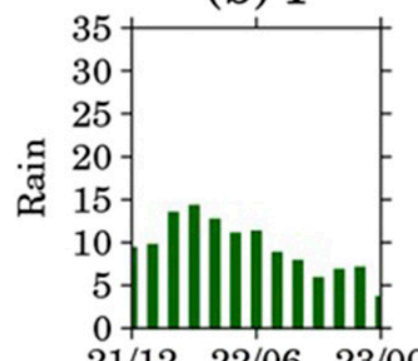

(c) II

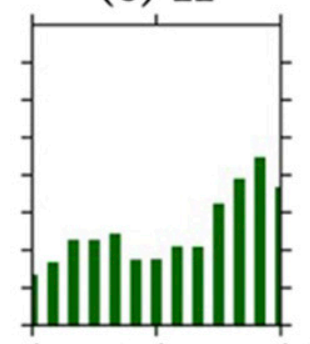

(d) III

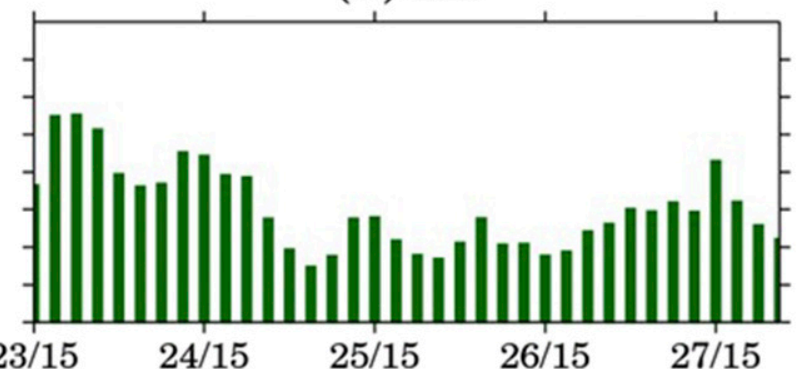

FIG. 5. Time-compass plot of (a) averaged 3-hourly accumulated rainfall (shaded, unit: mm) within 500-km radius; and (b)-(d) quadrant-averaged rain (unit: $\mathrm{mm}$ ) for (b) rain stage I averaged in the northwest quadrant; (c) II averaged over the southeast quadrant; and (d) III averaged over the southeast quadrant for the CTL simulation. The bold solid black line and dotted line denote the direction that the VWS and TC motion vectors point toward, respectively. The rainfall periods for I, II, and III are from 1200 UTC 21 Jan to 0000 UTC 23 Jan, 0300 UTC 22 Jan to 1500 UTC 23 Jan, and 1500 UTC 23 Jan to 0000 UTC 28 Jan 2013.

rainfall pattern with concentrated southeast (SE) quadrant rainfall (Fig. 5a). The VWS direction (solid black line) was well separated from the motion vector (dotted black line) in the early stage of the simulation. Two stronger rainfall areas were located in the northwest (NW) quadrant (downshear relative to VWS) and the southeast (SE) quadrants (the front quadrant relative to the motion vector) prior to 23 January. Subsequently, the VWS became more closely aligned with the motion vector with a small separation angle Accordingly, the rainfall asymmetry increased considerately in the SE quadrant (Deng and Ritchie 2018).

By attributing the three concentrated rainfall regions in Fig. 2 to the rainfall stages in Fig. 5a, the rainfall associated with Oswald can be separated into three main stages. The first center (I) near Weipa lasted from 21 to
23 January. The rainfall was mainly driven by convection in the NW quadrant of the TC (I indicated in Fig. 5a), with the maximum quadrant-averaged rain

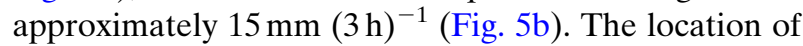
the rainfall was in the downshear side but opposite to the location expected due to TC motion, suggesting that the VWS might play an important role in generating the rainfall downshear compared to forcing due to the TC motion. In comparison, the second rainfall (II) near Townsville accumulated from 22 to 23 January was concentrated in the SE quadrant of the TC (II indicated in Fig. 5a). During this 36-h period, the averagedquadrant rainfall increased to a maximum of $18 \mathrm{~mm}$ $(3 \mathrm{~h})^{-1}$ (Fig. 5c). The forcing due to the TC motion and the VWS were well separated and the VWS magnitude was weak during the period of rainfall II. The rain area 
was located in the front quadrant relative to the moving $\mathrm{TC}$, which suggests that the motion-driven friction convergence might contribute to modulating the rainfall. The third rainfall center (III) to the south of Rockhampton was the longest and heaviest coherent rainfall region and lasted from 23 to 28 January. The rainfall occurred in two main periods from 23 to 25 January and after 27 January with the passage of two midlatitude troughs (Fig. 5d). The rainfall was mainly concentrated in the SE quadrant of the TC, generally aligned with both the shear direction and translation direction (III indicated in Fig. 5a). However, compared to the strong VWS (Fig. 4a), the motion speed of Oswald was only $4-6 \mathrm{~m} \mathrm{~s}^{-1}$ in the CTL simulation and the associated boundary friction relative to TC motion vector was less likely to be the main cause of the rainfall during this period. A more detailed analysis will be carried out in the next subsections to investigate the physical processes involving in each of the three rainfall areas.

\section{a. Rainfall area I}

The first rainfall region (I) was close to Weipa over the western Cape York Peninsula, where the terrain is very flat with an averaged elevation of approximately $100 \mathrm{~m}$ (Fig. 6a) and the effects due to topography can be ignored. The rainfall occurred in the northwest (downshear) quadrant from 1200 UTC 21 January to 0000 UTC 23 January. Prior to, and during this period the monsoon was active, and the increasing moist monsoon westerly flow moistened the air column, increasing the relative humidity to over $90 \%$ over the region prior to the arrival of Oswald (figure not shown). As Oswald approached the west coast of Cape York Peninsula, double rainfall bands were initiated downshear in the strong onshore wind (red wind vectors) on the equatorward side of Oswald's circulation in CTL. The maximum rain (more than $500 \mathrm{~mm}$ ) occurred near the land-sea boundary on the west coast centered at $12.5^{\circ} \mathrm{S}, 141.8^{\circ} \mathrm{E}$ and $13.6^{\circ} \mathrm{S}, 141.5^{\circ} \mathrm{E}$, respectively (Fig. 6b). During this period VWS was weak $\left(<5 \mathrm{~m} \mathrm{~s}^{-1}\right)$ (Fig. 4a) but provided weak forcing for rainfall development in the downshear quadrants. This is supported by the (albeit weaker) rainfall asymmetry in the northwest quadrant produced in the OCEAN simulation (Fig. 6d), which has no land forcing but does have VWS with a similar intensity. The two maxima in rainfall in CTL were collocated with boundary layer convergence maxima (Fig. 7a). From cross sections along the two convergence centers, vertical ascent can be seen along $12.5^{\circ} \mathrm{S}$ (Fig. 7c) and $13.6^{\circ} \mathrm{S}$ (Fig. 7d). The $900-1000 \mathrm{hPa}$ westerly onshore wind decreased along the land-sea boundary at $141.5^{\circ} \mathrm{E}$, converged, and then lifted upward to upper levels where divergence was generated (the warm shaded area in Figs. 7c,d). The reduced wind speed and enhanced convergence near the coastline occurred throughout the whole rainfall period I (Fig. 7b), which suggests that the enhanced convergence was directly related to the effect of land-sea boundary friction, rather than a transitory trailing rainband. This is supported by the two sensitivity simulations (Figs. 6c,d). The Hovmöller diagram of surface winds from CTL and TER (Figs. 8a,b) shows deceleration in winds across the coastline at $141.5^{\circ} \mathrm{E}$, which generated a strong surface convergence (black contours), ascent (red contours), and heavy rainfall center near Weipa. TER generated a double rainband pattern with two maxima (Fig. 6c) near the land-sea boundary similar to CTL although the height of the terrain was halved. The deceleration and generated rainfall in TER was stronger than that in CTL mostly because the simulated TC was more intense. In contrast to CTL and TER, the surface winds increased as the TC crossed the "coast" in OCEAN (Fig. 8c) because there was no interaction with the land and no corresponding frictional convergence and magnification of rainfall at the "coast." Instead, OCEAN offers some evidence that VWS forcing, although weak, may also contribute to the rainfall (Fig. 6d). However, it appears most likely that the onshore flow convergence was the main forcing for this rain event in the other simulations.

\section{b. Rainfall area II}

The second rain region (II) occurred in the more complex terrain near Cairns and Townsville (Figs. 6e,f), from 0300 UTC 22 January to 1500 UTC 23 January. During this period, Oswald started to move southward over land, but still maintained its circulation (Fig. 1). The maintenance of Oswald's circulation over land can be attributed to the monsoon trough where Oswald was embedded. The enhanced lower-level vorticity and high moisture within the monsoon trough results in a reduced Rossby deformation radius and increased efficiency of latent heating by moist convection. This in turn enhances the potential for vorticity aggregation and vertical development (Simpson et al. 1997; Wang et al. 2012), which would have helped to maintain the circulation against the effects of friction even after landfall.

Rainfall region II had a relatively complex structure with a maximum rainfall region of $550 \mathrm{~mm}$ on the coast (Fig. 2a). which was well captured by CTL (Fig. 2b). While the main rain occurred on the coast, the core of rainfall area II was initiated over the ocean within the broader TC circulation, in the onshore flow, and 

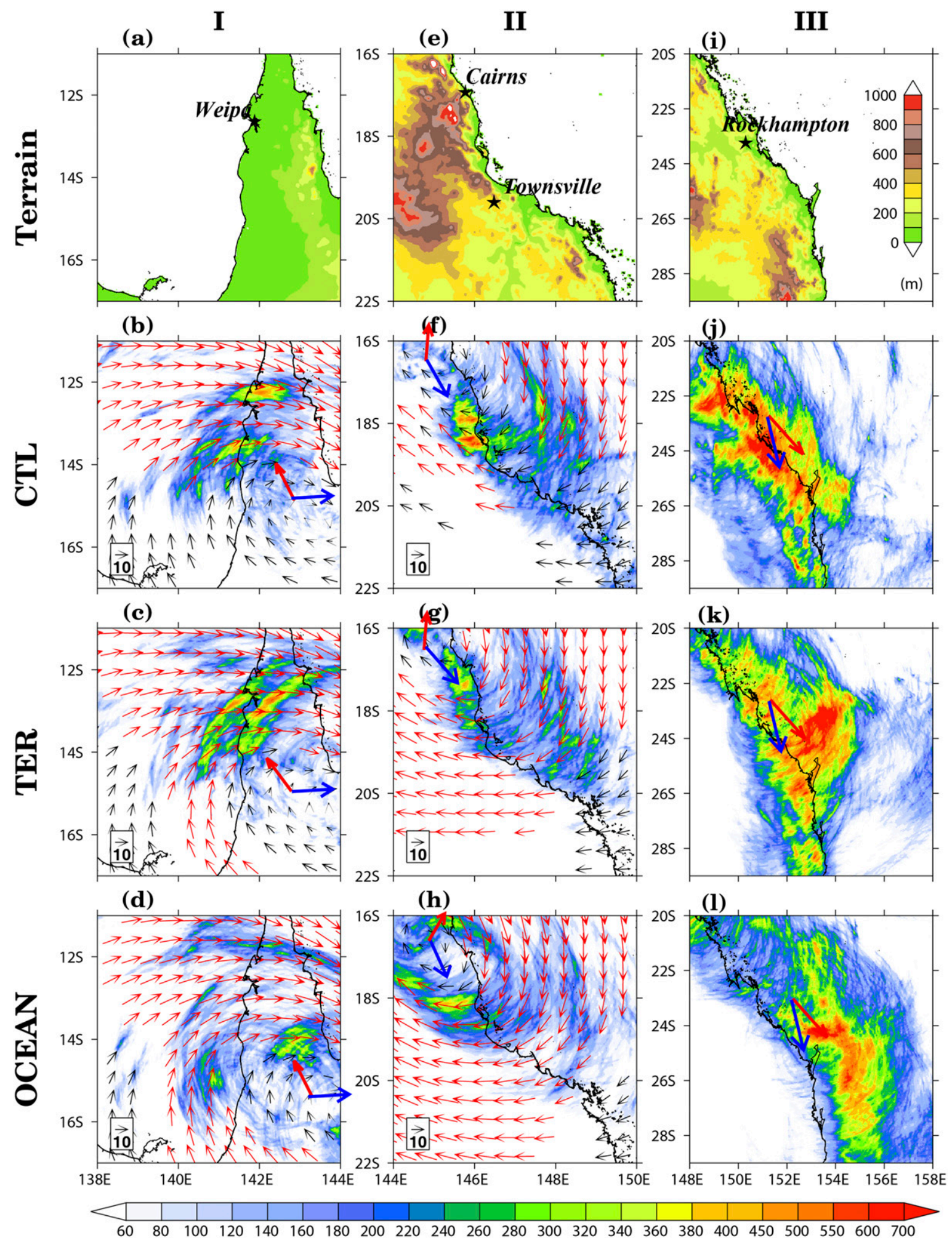

(k)

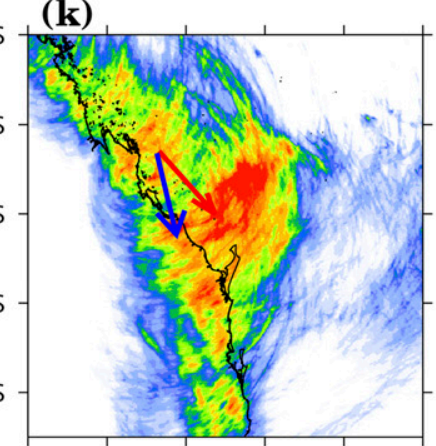

(l) 
(a)

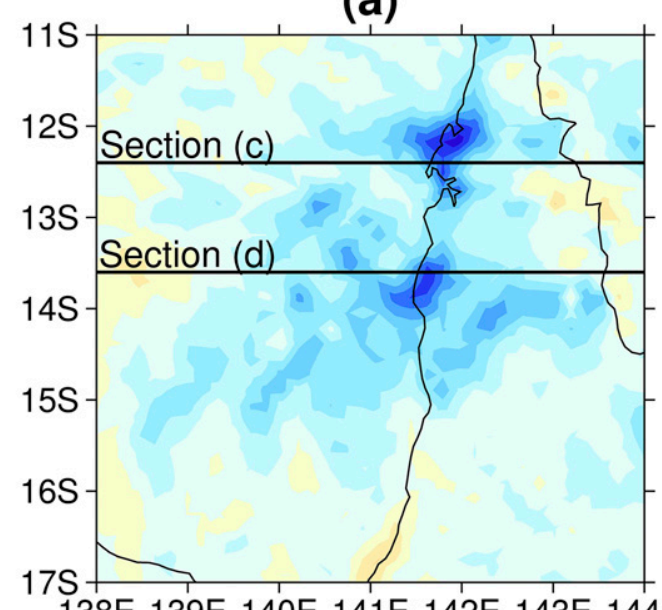

138E 139E 140E 141E 142E 143E 144E (c)

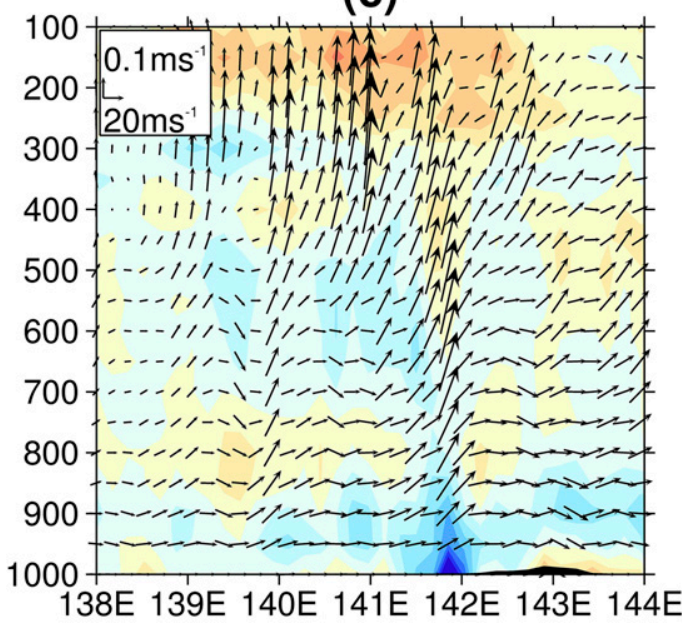

Time

(b)

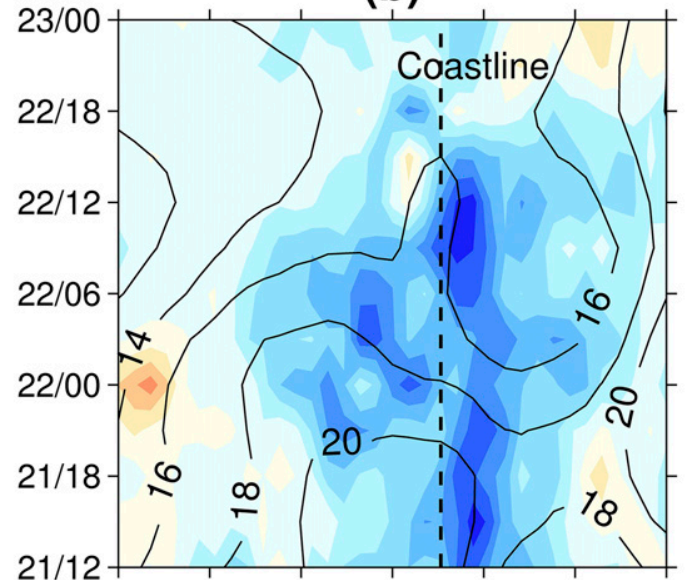

138E 139E 140E 141E 142E 143E 144E

Pres

(d)
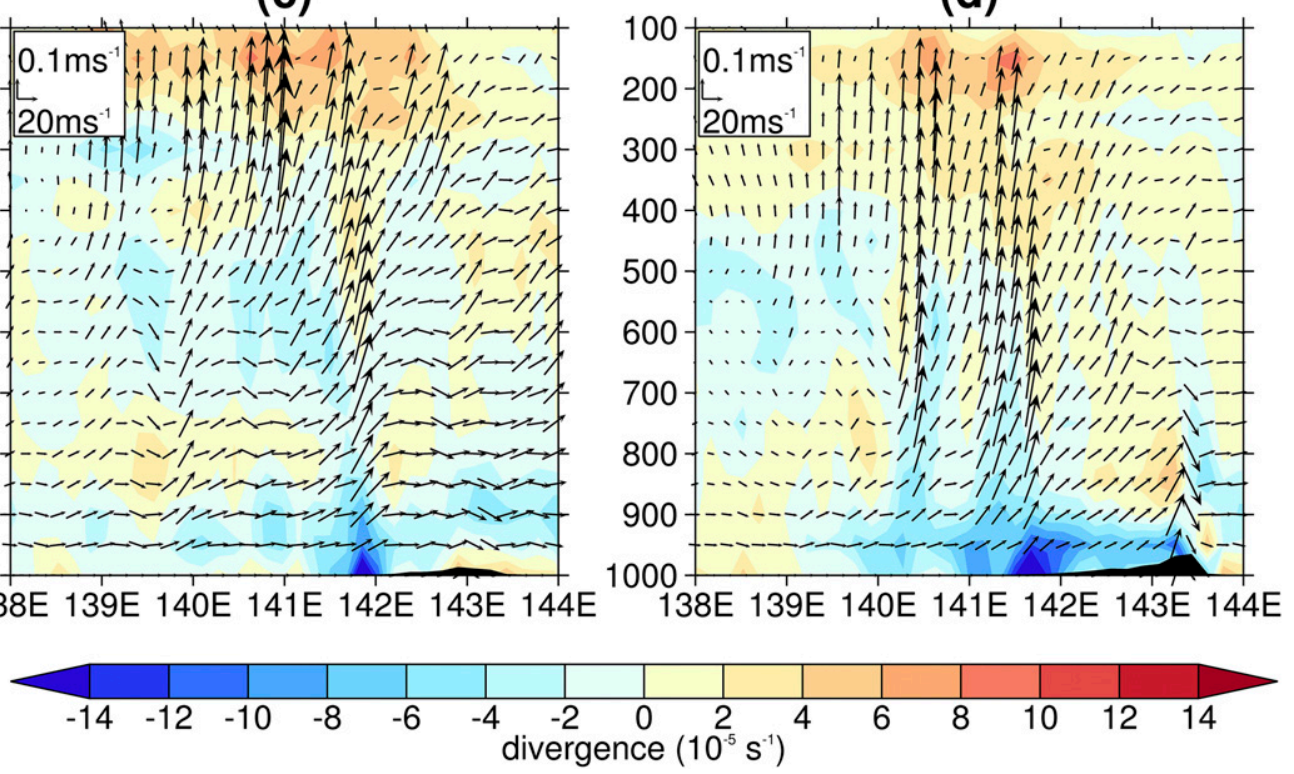

FIG. 7. The time-mean: (a) 1000-900 hPa divergence (unit: $10^{-5} \mathrm{~s}^{-1}$ ), and (b) time-longitude section of 1000$900 \mathrm{hPa}$ divergence and wind speed (contour, unit: $\mathrm{m} \mathrm{s}^{-1}$ ) averaged over $12^{\circ}$ to $14^{\circ} \mathrm{S}$; cross sections of divergence (shaded) and $\mathbf{u}-\mathbf{w}$ vector along (c) $12.5^{\circ} \mathrm{S}$ and (d) $13.6^{\circ} \mathrm{S}$ for rainfall region I in CTL. The time is averaged from 1200 UTC 21 Jan to 0000 UTC 23 Jan 2013. The two solid lines in (a) indicate the cross sections in (c) and (d), respectively. The dashed line in (b) denotes the location of the coastline.

maximized over the coastal terrain (Fig. 6f). Several factors were associated with the development of this rainfall structure. In CTL, boundary layer convergence was distributed in widespread regions in front of the TC from 400 to $500 \mathrm{~km}$ away from the coast to a maximum on the coast (Figs. 9a,b). Several bands of vertical motion were also apparent (Fig. 9c) originating from bands of boundary layer convergence extending at least $300 \mathrm{~km}$ offshore, with a maximum region just onshore. The magnitude of the onshore wind associated with Oswald was greatly reduced at the coastline especially near the mountainous areas north of Townsville (Fig. 6f). This wind deceleration resulted in regions of coastal low-level convergence, enhanced updrafts, and mid- to upper-level divergence on the windward slope (Figs. 9a,c), overlapping with the relatively higher moisture flux convergence (figure not shown) and orographically enhanced rainfall regions (Fig. 6f). To provide a more quantitative evaluation on whether the enhanced windward ascent is related to topographic lifting, the terrain forced vertical motion equation is solved using the expression, 
(a) CTL

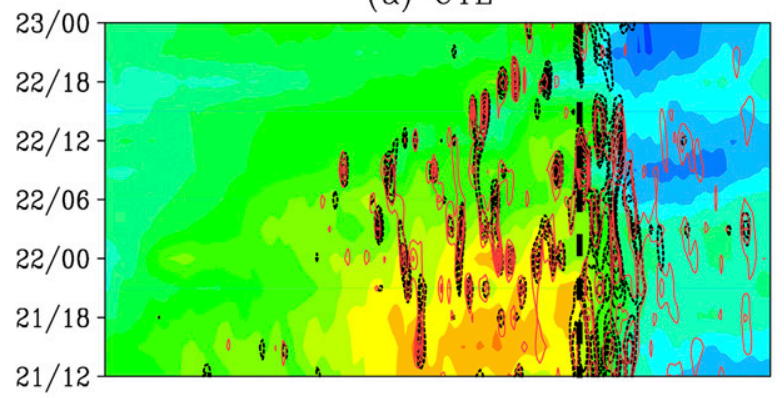

(b) TER

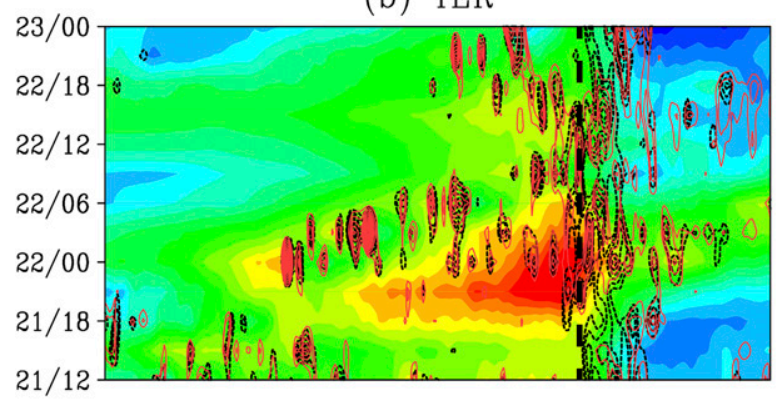

(c) OCEAN

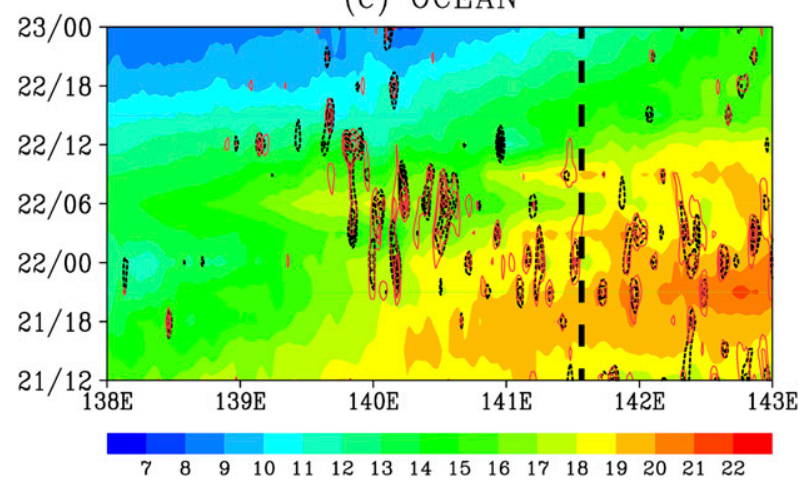

FIG. 8. Time-longitude Hovmöller diagram averaged in the latitude band from $12^{\circ}$ to $14^{\circ} \mathrm{S}$ for surface wind speed (shaded, unit: $\mathrm{m} \mathrm{s}^{-1}$ ), divergence (black dotted contours: $\leq-15 \times 10^{-5} \mathrm{~s}^{-1}$ ), and 900-hPa ascent (red contours: $\geq 0.1 \mathrm{~m} \mathrm{~s}^{-1}$ ) for rainfall region I in: (a) CTL, (b) TER, and (c) OCEAN. The bold dashed line denotes the location of the coastline near Weipa.

$$
W_{\text {terrain }}=u \frac{\partial h}{\partial x}+v \frac{\partial h}{\partial x},
$$

at a model level of $\sigma=0.993$ following Wu et al. (2002) and Yu and Cheng (2008). Here, $h$ is the terrain height, and $u$ and $v$ are the zonal and meridional winds, respectively. In Eq. (1) topographically forced vertical motion is proportional to the steepness of the mountain slope along the wind direction of oncoming flow. Equation (1) has been used in many previous studies to evaluate orographic lifting (e.g., Wu et al. 2002; Yu and Cheng 2008). The distribution of $W_{\text {terrain }}$ coincides well with the total vertical motion with the ascent on the windward and descent on the leeward slopes extending from $17^{\circ}$ to $19^{\circ} \mathrm{S}$ during the period of rainfall region II. This suggests that the lower-level enhanced ascent on the windward side is due to orographic lifting rather than forcing due to synoptic or mesoscale systems. Although the orographic lifting is not strong $\left(\sim 10 \mathrm{~cm} \mathrm{~s}^{-1}\right)$ near the surface, given the convectively unstable (partly neutral) and high CAPE environment on the windward slope (Fig. 9e), the increase in buoyant force on air parcels being displaced by orographic lifting would be significant. The transient updraft increased to a maximum of $2 \mathrm{~m} \mathrm{~s}^{-1}$ in the middle atmosphere (not shown), collocated with the higher than $40 \mathrm{dBZ}$ reflectivity on the windward slope (Fig. 9d). In contrast, on the lee side, the drying, reduced instability, and low CAPE air inhibits convective development, thus, a downdraft was produced (Fig. 9c). This configuration is similar to the features of topographic precipitation in Dominica shown by Smith et al. (2009a,b).

The proposed rainfall mechanism over the coast is further supported by two sensitivity experiments. In the TER sensitivity simulation with a halved terrain elevation, there was much less deceleration of the onshore flow at the coast compared with CTL (Fig. 6g). There was correspondingly weaker low-level convergence along the coast and as a result, a weaker linear rainfall band (Fig. 6g). In the OCEAN sensitivity simulation, which had no land surface at all, there was no frictional deceleration of the easterly winds to the south of the TC center, no orographic uplift, and no corresponding linear band of coastal rainfall (Fig. 6h).

If the only mechanisms for vertical motion were frictional convergence due to the deceleration of the onshore wind at the coast and the orographic lifting, then the rainfall would be distributed only along the coastal range. However, there is additional rain located offshore to the south of Oswald's center in CTL. There are two other possible mechanisms that can modulate vertical motion in the TC circulation that could produce this persistent pattern of rainfall: a wavenumber-1 vertical motion asymmetry due to environmental VWS (Frank and Ritchie 1999, 2001); and boundary layer convergence due to the TC motion (Shapiro 1983; Frank and Ritchie 1999, 2001). As we have shown previously, it was unlikely that the very weak VWS contributed to the rainfall since the rainfall was not collocated with the VWS forcing. To examine whether boundary layer convergence due to the TC motion could be responsible for the pattern of rainfall offshore to the south of the TC center, the OCEAN simulation is first examined because it lacks the strong onshore and orographic forcing of the other two simulations. In OCEAN, the rainfall is distributed in a more circular pattern around the vortex, compared with CTL or TER because there is no coastal 
(a)

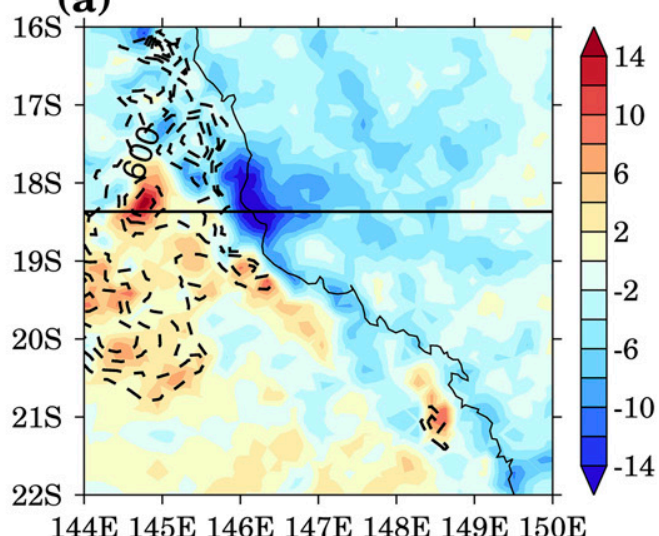

144E 145E 146E 147E 148E 149E 150E

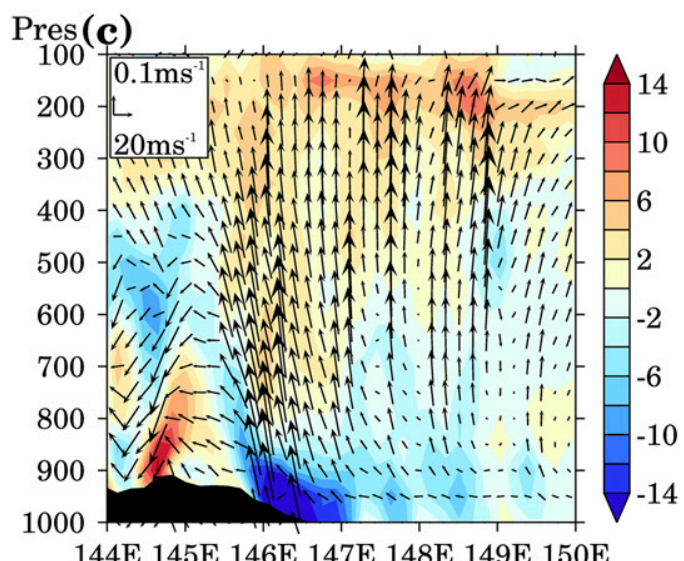

\section{$\operatorname{Pres}(\mathbf{e})$}

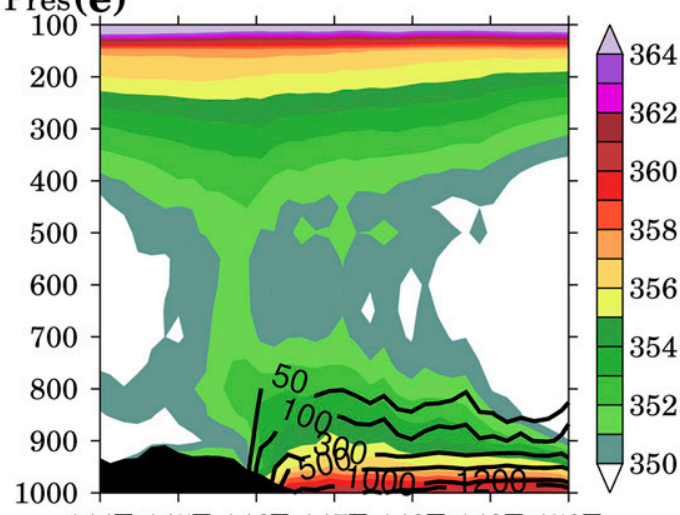

$144 \mathrm{E} 145 \mathrm{E} 146 \mathrm{E} 147 \mathrm{E} 148 \mathrm{E} 149 \mathrm{E} 150 \mathrm{E}$

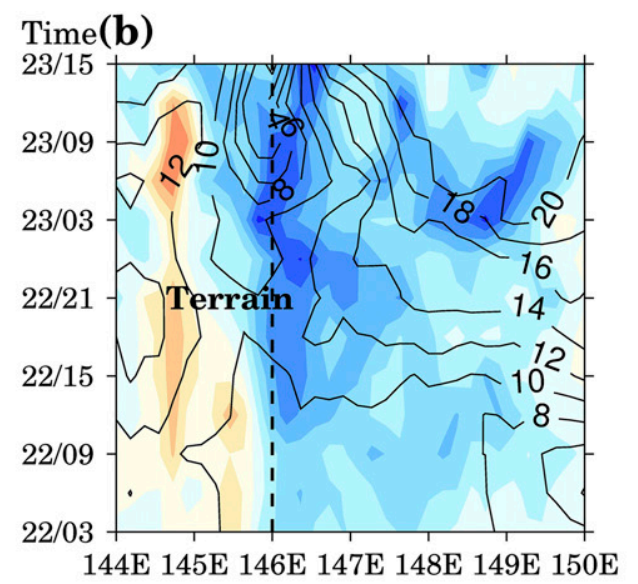

$\operatorname{Pres}(\mathbf{d})$

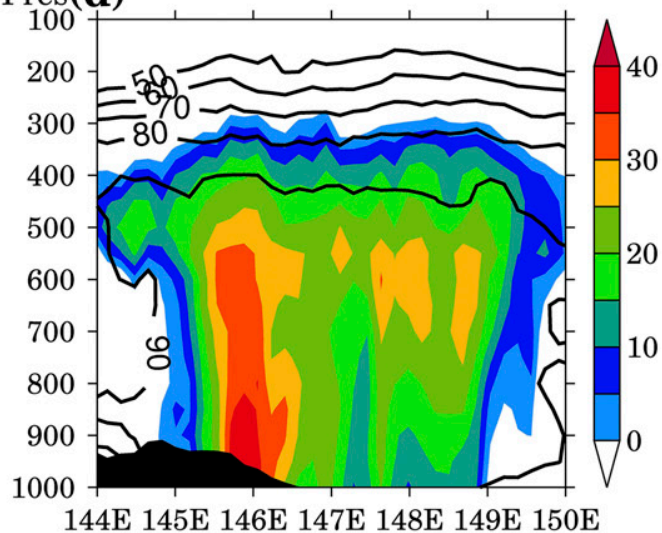

(f)

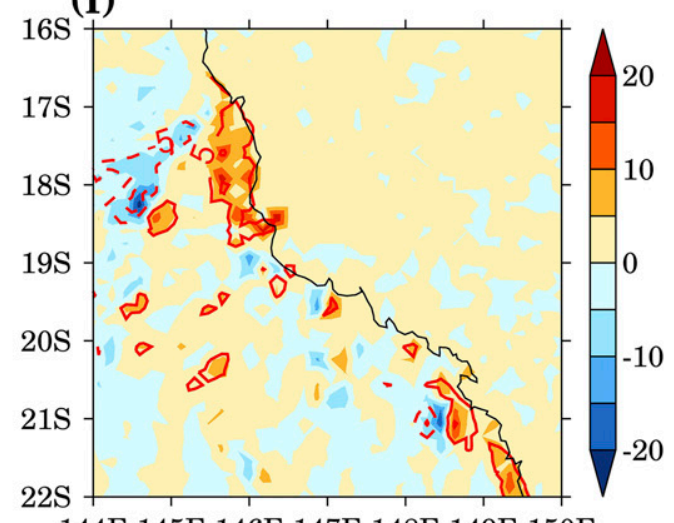

144E 145E 146E 147E 148E 149E 150E

FIG. 9. The time-mean: (a) 1000-900 hPa divergence (unit: $10^{-5} \mathrm{~s}^{-1}$ ), and (b) time-longitude section of 1000$900 \mathrm{hPa}$ divergence and wind speed (contour, unit: $\mathrm{m} \mathrm{s}^{-1}$ ) averaged over $17^{\circ}$ to $19^{\circ} \mathrm{S}$; and $18.4^{\circ} \mathrm{S}$ pressure-longitude cross sections of (c) divergence (shaded, unit: $10^{-5} \mathrm{~s}^{-1}$ ) and $\mathbf{u}-\mathbf{w}$ vertical vector circulation, (d) reflectivity (shaded, unit: $\mathrm{dBZ}$ ) and relative humidity (black contour, unit: \%), (e) equivalent potential temperature (shaded, unit: K) and CAPE (black contour, unit: $\mathrm{J} \mathrm{kg}^{-1}$ ), and (f) total vertical motion (shaded, unit: $10^{-2} \mathrm{~m} \mathrm{~s}^{-1}$ ) and topographically induced vertical motion (red contour) at $\sigma=0.993$ for rainfall region II in CTL. The time is averaged from 0300 UTC 22 Jan to 1500 UTC 23 Jan 2013 . The TC center in (a) for the time average is located near $\left(16.1^{\circ} \mathrm{S}\right.$, $\left.144.8^{\circ} \mathrm{E}\right)$. The solid line in (a) shows where the cross sections in (c)-(e) are located and the dashed contours denote the terrain height. The bold dashed line in (b) denotes the location of the terrain. 
boundary (Figs. 6f-h). Furthermore, Fig. 6h exhibits characteristics of TC-motion-induced boundary layer forced frictional inflow and convergence (Shapiro 1983) with enhanced rainfall in the front quadrant, and reduced rainfall in the rear quadrant with a forward motion speed ranging from 4 to $8 \mathrm{~m} \mathrm{~s}^{-1}$ (average $5 \mathrm{~m} \mathrm{~s}^{-1}$ ) during this period (Fig. 4a). The asymmetric rain area in OCEAN matches the offshore rain region in CTL suggesting that TC-motion-induced boundary layer frictional convergence might also be a factor that impacts and modulates the rainfall just offshore in CTL. However, the signal in CTL is likely masked by the strong onshore frictional convergence and orographic uplift previously discussed. Figure $9 \mathrm{c}$ shows several bands of boundary layer convergence with associated deep vertical motion in the front quadrant region relative to the TC motion in CTL east of the coastline. It is likely that some of this region is associated with TC motion-induced boundary layer convergence.

Thus, it is concluded that the rainfall II center near Townsville can be attributed primarily to the joint effects of local orographic uplift and convergence due to deceleration of the onshore wind from increased friction at the coast, with TC motion-induced frictional convergence providing some modulation of the offshore rainfall in a high moisture, high CAPE monsoonal environment.

\section{c. Rainfall area III}

The third rainfall area (III) was located near and to the south of Rockhampton, which has an averaged topographic elevation of only $200-400 \mathrm{~m}$ (Fig. 6i). This region experienced the longest-lasting and most disastrous heavy rainfall and flooding (Fig. 6j). As Oswald moved southward, the heavy rainfall region III extended as far south as $29^{\circ} \mathrm{S}$, with majority areas along the coast exceeding $500 \mathrm{~mm}$ (Figs. 2 and 6j). The southward extent of the rainfall means that extratropical forcing may also be important in producing the heavy rainfall and the sensitivity simulations, particularly OCEAN, are important to help determine the extent of extratropical forcing versus other mechanisms already discussed for the previous 2 rainfall regions. However, the simulated vortex in OCEAN moved southward more rapidly compared to the other two simulations (CTL and TER) and the observations (Fig. 1a). Therefore, to compare the mechanisms for the heavy rainfall processes among the three simulations, the analysis time period used for OCEAN is adjusted so that the rainfall area in OCEAN corresponds with the other two simulations and with the actual rainfall event. The period of analysis for OCEAN is 0300 UTC 23 January to 0000 UTC 27 January ( $93 \mathrm{~h}$ ) compared with 1500 UTC 23 January to 0000 UTC
28 January (105h) for CTL and TER (Figs. 6j,k). Generally, the shape and size of the primary rain swaths in both TER and OCEAN are similar to CTL, presented in an elongated northwest-southeast oriented pattern, except that the swath for TER is located slightly east of CTL with an additional rain area offshore, and OCEAN is located entirely offshore. The slight differences in the location of the rain swath can be attributed to the differences in the simulated vortex tracks (Fig. 1a) and may also be affected by underlying topography and land-sea contrast. In addition, compared to CTL and TER, the rainfall in OCEAN was slightly weaker, which may be influenced by the shorter duration ( 93 vs $105 \mathrm{~h}$ ) and lack of land-sea surface friction convergence and topography. However, the general shape and amount of rainfall in OCEAN is very similar to CTL and TER. Since OCEAN does not include the underlying surface and terrain of TER and CTL, the impact of the two midlatitude troughs passing to the south of TC Oswald described in section 3 (Fig. 3) will be the focus of the analysis of rainfall mechanisms for rainfall III.

Figure 10 shows the same two representative times from Fig. 3 at 0000 UTC 24 January and 1500 UTC 27 January, respectively, to highlight how Oswald responded to the passage of the two midlatitude troughs. Backward trajectories from Oswald's circulation (Figs. 10c,d, a total of 81 grid points) and from the outer southeast quadrant where the heaviest rainfall occurred (Figs. 10e,f, a total of 26 grid points) from Oswald's circulation are calculated using the HYSPLIT model starting at a height of $7 \mathrm{~km}$ (close to $400 \mathrm{hPa}$ ). As the first midlatitude trough approached, the southsouthwestern cyclonic PV air from the trough was transported into the TC circulation, reflecting the direct environmental injection of high PV air (Figs. 10a,c). In the meantime, the high PV particles (with up to 3 PUV) within the inner Oswald circulation were transported outward by northerlies ahead of the trough to the southeast quadrant of Oswald (Fig. 10e), where strong dynamical lifting and heavy rainfall can be seen (blue contours in Fig. 10a). Similarly, the environmental PV injection by the southwesterly flow from the trough and PV ejection by the northerly flow from Oswald to the outer southeastern quadrant can also be seen during the passage of the second trough (Figs. 10b,d,f). During the two interactions, the southwest cyclonic PV injection was transported radially inward (from $1000 \mathrm{~km}$ away from the TC center to within $200 \mathrm{~km}$ ) and downward from mid- to upper levels to the lower-level TC circulation during the two TC-trough interactions, resulting in an increase in the PV on the southwestern side of Oswald's circulation (figure not shown). The replenishment of cyclonic PV from the two troughs, also reflected 
(a) 00 UTC 24 Jan

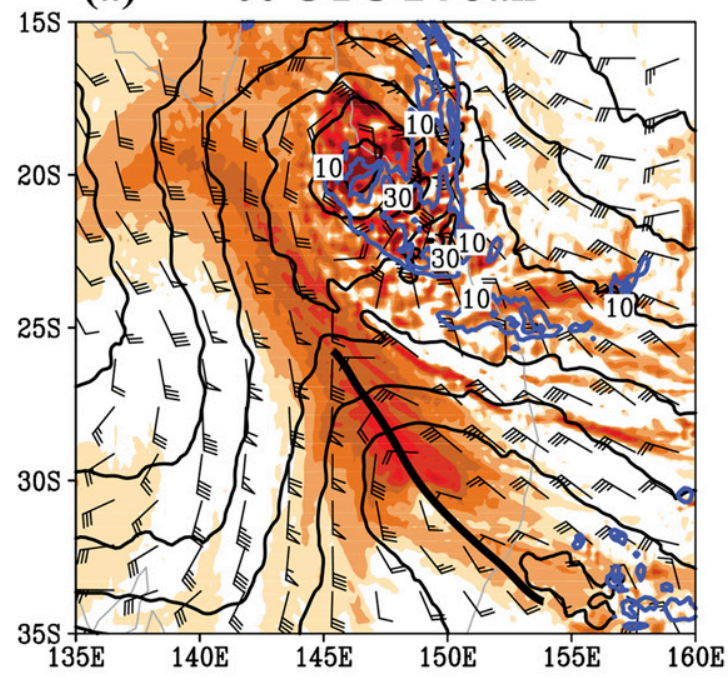

(c) 0-5 degrees

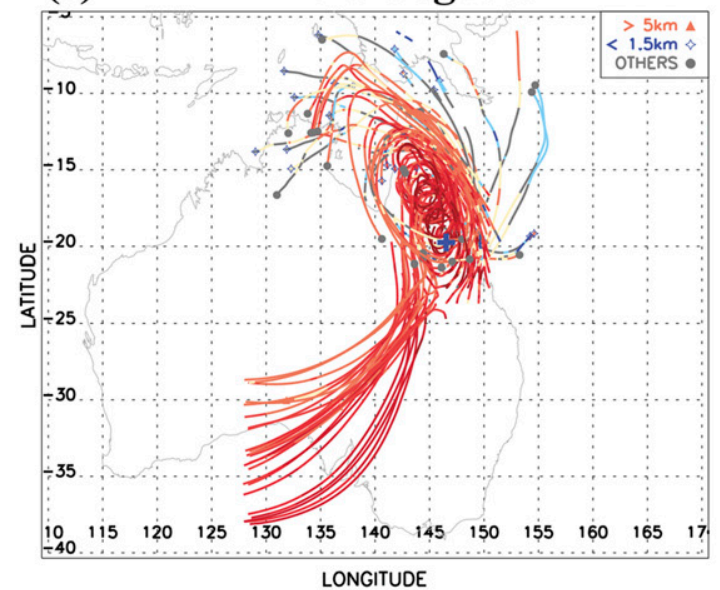

(e) 1-5 degrees SE quadrant

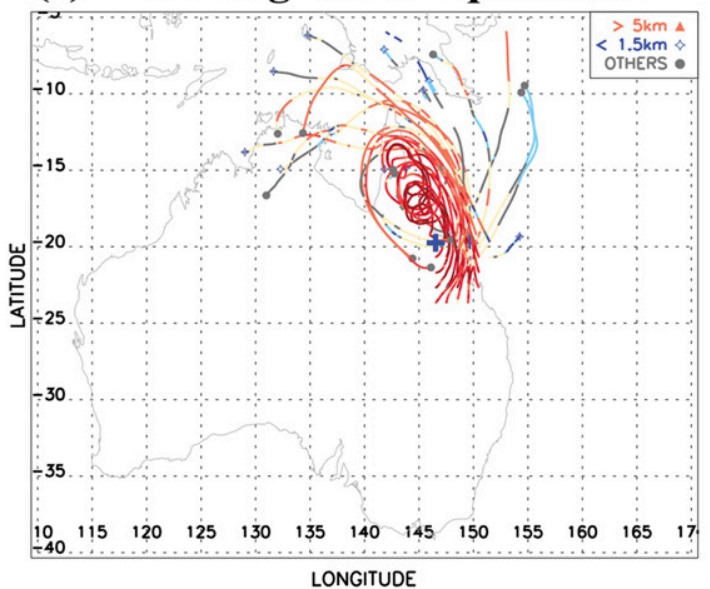

(b) 15 UTC 27 Jan
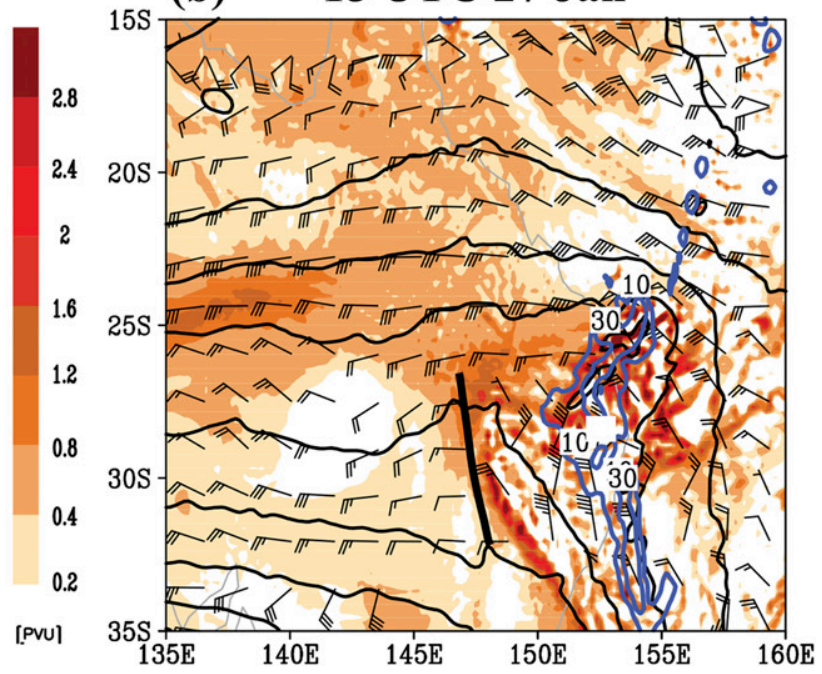

(d)
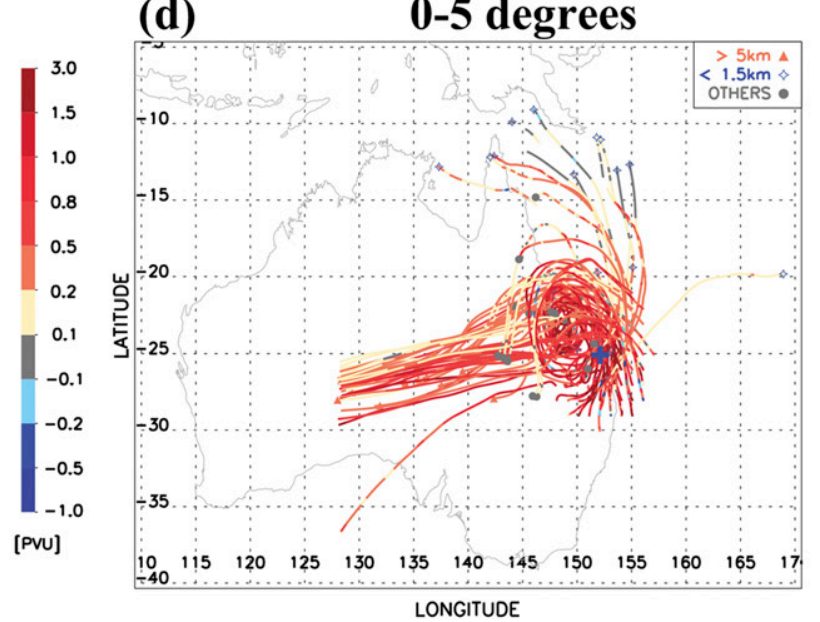

(f) 1-5 degrees SE quadrant

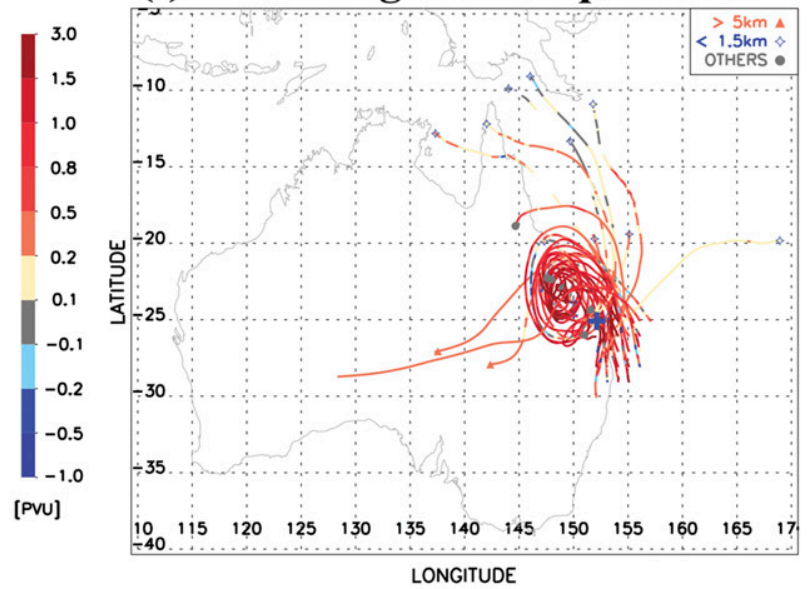

FIG. 10. (a),(b) 400-hPa PV (shaded: cyclonic PV, unit: - PVU (1 PVU $=10^{-6} \mathrm{~K} \mathrm{~kg}^{-1} \mathrm{~m}^{2} \mathrm{~s}^{-1}$ ), wind, geopotential height (black contour, interval: $20 \mathrm{~m}$ ), and $3-\mathrm{h}$ accumulated rainfall $\left[10 \mathrm{~mm}(3 \mathrm{~h})^{-1}\right.$ and $30 \mathrm{~mm}(3 \mathrm{~h})^{-1}$ are plotted in blue]; horizontal plots of $48-\mathrm{h}$ backward trajectories from (c),(d) Oswald circulation (within $5^{\circ}$ of radius) and (e),(f) the outer southeast quadrant of Oswald circulation (a southeast annulus between $1^{\circ}$ and $5^{\circ}$ of radius) at the starting time for (a),(c),(e) 0000 UTC 24 Jan, (b),(d),(f) 1500 UTC 27 Jan 2013 . The initial parcel elevation is $7 \mathrm{~km}$. The color denotes different PV values (unit: -PVU) as shown in the color bar. 
in the inward propagation of relative eddy momentum flux convergence (figure not shown), provides a direct dynamical driver for the spinup of Oswald's remnants (e.g., Figs. 1b and 4c). Because of the continuous replenishment from the two troughs, Oswald's circulation maintained intensity over land for 5 days during this period. However, as the focus here is on the TC rainfall processes, more details of how the environmental PV injections affect the TC structure and intensity will be presented in a follow-up paper.

From Fig. 5a, the heaviest rain was generated in the southeast quadrant of the Oswald circulation during two periods; 1500 UTC 23 January-0000 UTC 25 January; and 0000 UTC 27 January-0000 28 January, respectively, which coincided with the passage of the two midlatitude troughs and the PV ejection from the inner-core of Oswald to the southeast (Figs. 10e,f). To analyze this heavy rainfall period, the time-mean horizontal distribution and cross sections along the heaviest rain region (line from A to B shown in Fig. 11a) are presented in Figs. 11 and 12 for the first TC-trough interaction. The most torrential rainfall on the southeast of Oswald was coincident with the strong ascent at mid- to upper levels (gold shading in Fig. 11a), which was located just beneath the equatorward side of the upper-level jet entrance region. The northwesterly flow ahead of the trough not only increased the midlevel TC radial outflow (Fig. 4c), it also contributed to the increase of cyclonic vorticity advection (Fig. 11c), and warm advection (Fig. 11d) to the southeast of Oswald, which are favorable synoptic dynamical forcings for ascent (Fig. 12). Figure 11a shows the asymmetric vortex circulation that had developed with decreasing winds in the upshear (toward A) direction and increasing winds in the downshear (toward B) direction. Strong midto lower-level convergence and upper-level divergence were organized in the downshear direction, just beneath the equatorward side of the upper-level jet entrance region. The strongest cyclonic vorticity was located near the center of Oswald at mid- to lower levels, while the cyclonic vorticity advection (red contours in Fig. 12b) and warm advection (red shaded in Fig. 12c) advected approximately $2^{\circ}$ to $5^{\circ}$ latitude downshear of the TC center at mid- to upper levels (700-200 hPa). The strongest cyclonic vorticity advection was located $200-500 \mathrm{~km}$ away from the TC center at mid- to upper levels, which is consistent with the cyclonic PV ejection from the innercirculation to the outer southeast quadrant in the trajectory analysis (Fig. 10e). A strong $\mathbf{Q}$-vector convergence (blue contour in Fig. 12d) and corresponding updraft (red shaded) were generated due to the dynamic and thermodynamic forcing. During this period, the frontogenesis was relatively weak (Fig. 11b). Therefore, the outward transport of cyclonic vorticity or PV, warm advection, and associated Q-vector convergence in response to the first TC-trough/jet interaction, along with the abundant moisture supply (Fig. 12c), provided favorable dynamical lifting for the development of convection in the southeast quadrant of Oswald.

During the second TC-trough interaction, the circulation of Oswald was increasingly embedded into the midlatitude trough compared to the first interaction. The heaviest rainfall, overlaid with an elongated midlevel ascent region (gold shading) in Fig. 13a, consisted of two connected areas. One was located directly within the southeast quadrant of Oswald. The other was a linear rainfall band extending southward from Oswald farther toward the midlatitudes, from $30^{\circ}$ to $36^{\circ} \mathrm{S}$, which aligned with the isopleth of geopotential ahead of the midlatitude trough. Similar to the first interaction, the increasing northerly flow ahead of the trough, resulted in higher environmental VWS, which contributed to an increase in the midlevel TC radial outflow (Fig. 4c), high cyclonic vorticity advection (Fig. 13c), and strong warm advection (Fig. 13d) from the TC circulation to outer radii in the southeast. Correspondingly, the cross section along line A-B in Fig. 14 presents a more asymmetric, downsheartilted TC circulation, collocated with strong lower- to midlevel convergence and upper-level divergence in the downshear direction, beneath the upper-level jet streak (Fig. 14a). The active cyclonic vorticity advection (red contours in Fig. 14b, partly reflected in the strong PV ejection from inner-circulation to the southeast in Fig. 10f, and warm advection (yellow shaded in Fig. 14c) was tilted between $2^{\circ}$ and $10^{\circ}$ latitude downshear from the vortex center at mid- to upper levels. Q-vector convergence (blue contour) and a widespread updraft (shaded) developed as a result (Fig. 14d). In addition, as the warmer Oswald circulation intruded into the relatively colder midlatitudes, a north-south-orientated frontal zone formed over land indicated by the strong gradient in equivalent potential temperature, with frontogenesis values of up to $8 \times$ $10^{-9} \mathrm{~K} \mathrm{~s}^{-1} \mathrm{~m}^{-1}$ (Fig. 13b). This frontogenesis region was overlaid with the large linear rainfall band. The cross section perpendicular to the front (along C-D in Fig. 13a), shows frontal vertical structure (Fig. 14e) with a large gradient in equivalent potential temperature extending from 300 to $900 \mathrm{hPa}$ and strong frontogenesis at $154^{\circ} \mathrm{E}$ (up to $8 \times 10^{-9} \mathrm{~K} \mathrm{~s}^{-1} \mathrm{~m}^{-1}$ ) at mid- to lower levels (Fig. 14e). Easterly flow into the front from the east rose upward along the frontal surface to $200 \mathrm{hPa}$, where it turned westerly in the upper-level westerly flow (Fig. 14f). In response, $\mathbf{Q}$-vector convergence and the frontal updraft were maximized near the surface front at $154^{\circ} \mathrm{E}$. Thus, in addition to the enhanced quasigeostrophic dynamical forcing (e.g., differential cyclonic vorticity (PV) advection, warm advection, and associated $\mathbf{Q}$-vector convergence) ahead of 
(a)

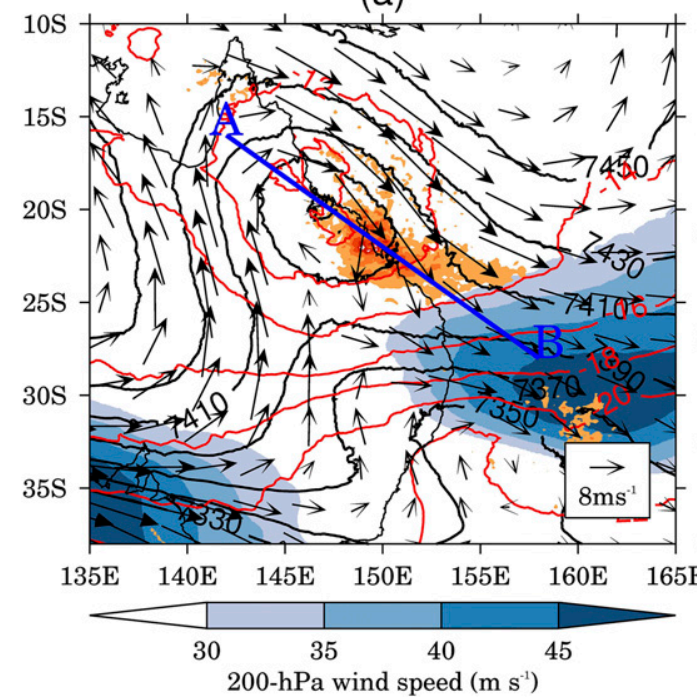

(c)

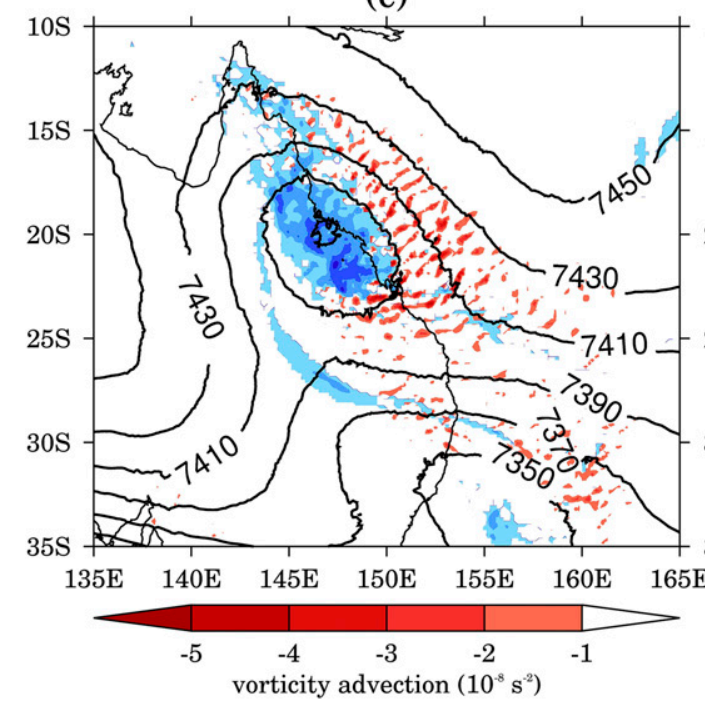

(b)

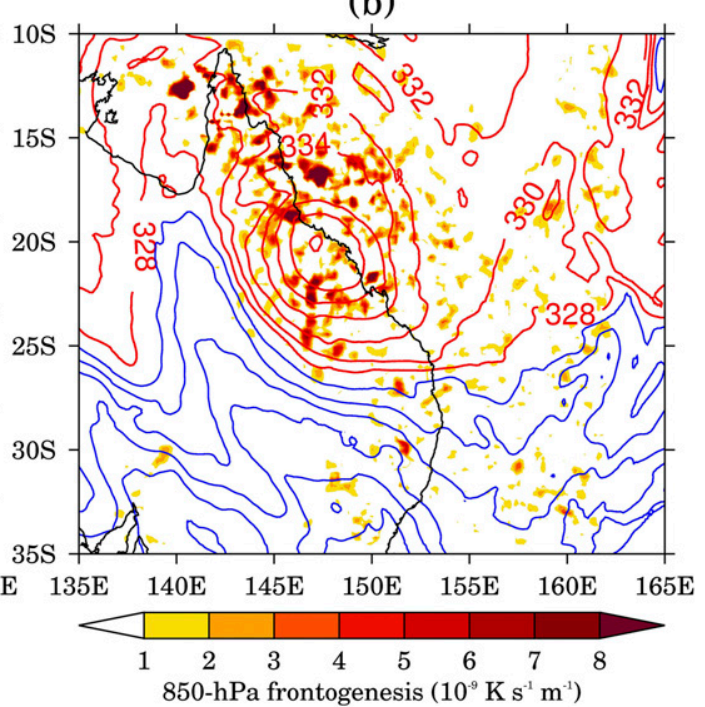

(d)

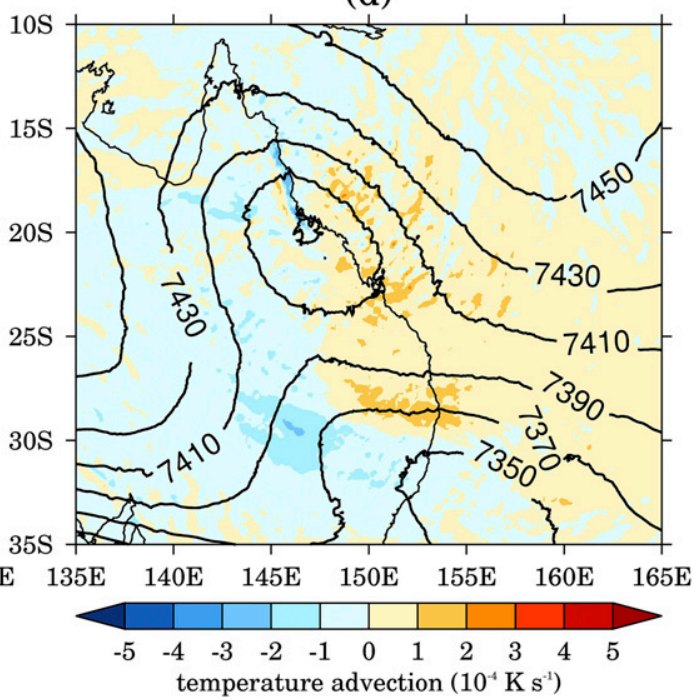

FIG. 11. Time-mean horizontal plots from 1200 UTC 23 Jan to 0000 UTC 25 Jan 2013: (a) 400-hPa geopotential height (black contour, intervals: $20 \mathrm{dam}$ ), temperature (red contour, intervals: $2 \mathrm{~K}$ ), upward motion (gold shaded: $\geq 0.1 \mathrm{~m} \mathrm{~s}^{-1}$ ) and wind vectors, and 200-hPa wind speed (blue shaded: $\geq 30 \mathrm{~m} \mathrm{~s}^{-1}$ ); (b) 700-hPa equivalent potential temperature (intervals: $2 \mathrm{~K}$, blue/red contours: lower/higher than $328 \mathrm{~K}$ ) and 850 -hPa frontogenesis function (red shaded, unit: $10^{-9} \mathrm{~K} \mathrm{~s}^{-1} \mathrm{~m}^{-1}$ ); (c) 400 -hPa vorticity (blue shaded: $\leq-1 \times 10^{-5} \mathrm{~s}^{-1}$ ), horizontal vorticity advection (red shaded: $\leq-1 \times 10^{-8} \mathrm{~s}^{-2}$ ), and geopotential height (black contour); and (d) 400-hPa horizontal temperature advection (shaded, unit: $10^{-4} \mathrm{~K} \mathrm{~s}^{-1}$ ) and geopotential height (black contour).

the midlatitude trough, which provided the forcing for the heavy rain in the southeast quadrant of Oswald, the frontal forcing provided additional lifting for the large linear rainband extending to the south.

\section{Discussion and conclusions}

Oswald (2013) was a weak category-1 TC but is one of the highest-impact storms making landfall in northern
Australia. After making landfall, its remnant circulation lasted for more than 7 days over land and produced three extreme rainfall events with the accumulated rainfall exceeding $500 \mathrm{~mm}$ along the east coast near Weipa, Townsville and to the south of Rockhampton, respectively. Using high-resolution WRF simulations, the rainfall mechanisms for the three main rainfall regions are investigated. The results show that Oswald was influenced by multiple external forcings including the 

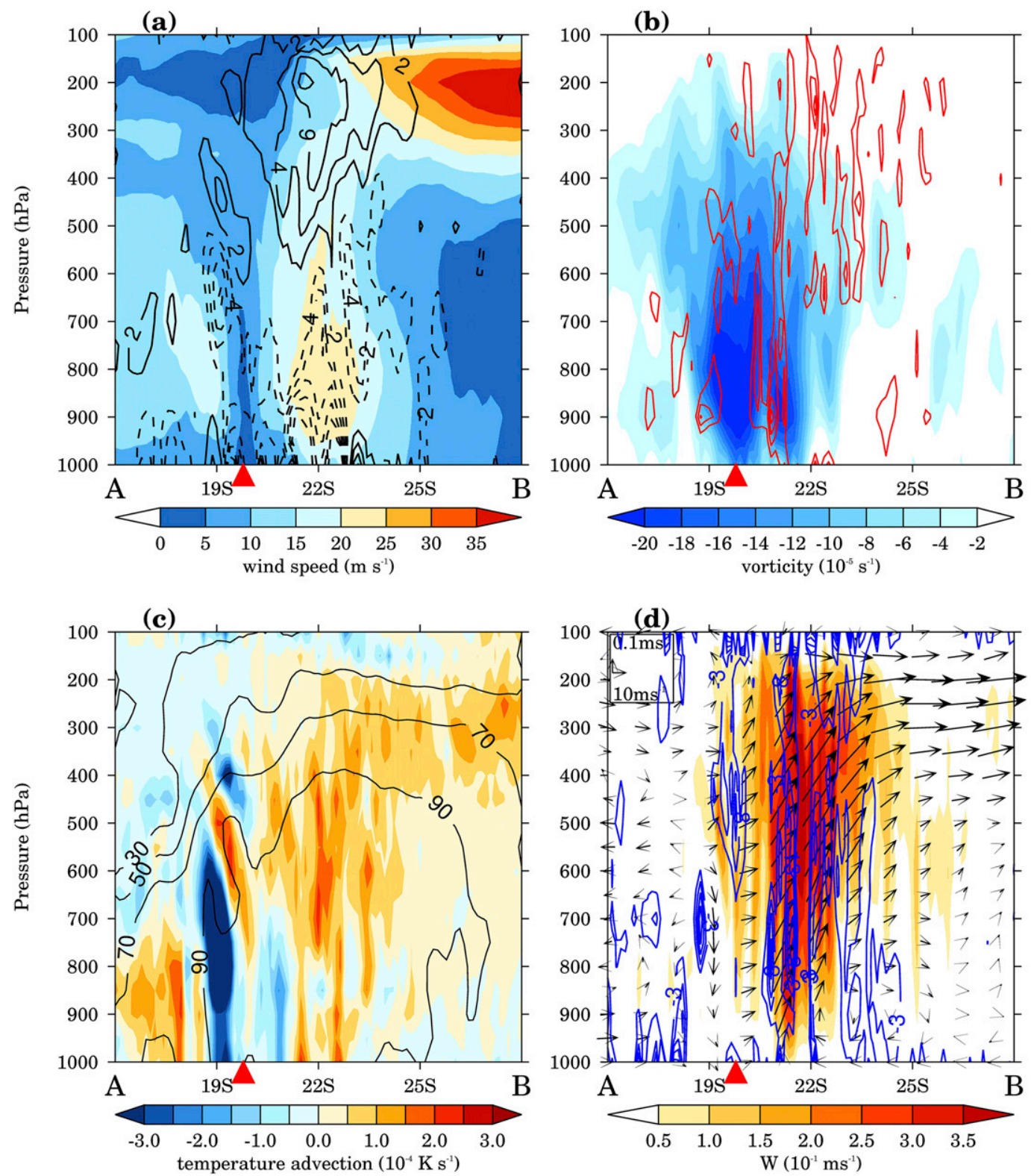

FIG. 12. Time-mean cross sections along line A-B in Fig. 11a from 1200 UTC 23 Jan to 0000 UTC 25 Jan 2013 for: (a) horizontal wind speed (shaded, unit: $\mathrm{m} \mathrm{s}^{-1}$ ) and divergence (contours, intervals: $2 \times 10^{-6} \mathrm{~s}^{-1}$ ); (b) vorticity (blue shaded: $\leq-2 \times 10^{-5} \mathrm{~s}^{-1}$ ) and horizontal vorticity advection (red contour: $\leq-1 \times 10^{-8} \mathrm{~s}^{-2}$ ); (c) horizontal temperature advection (shaded, unit: $10^{-4} \mathrm{~K} \mathrm{~s}^{-1}$ ) and relative humidity (contour: unit: \%); and (d) Q-vector divergence (blue contours: $\leq-3 \times 10^{-11} \mathrm{~J} \mathrm{~kg}^{-1} \mathrm{~m}^{-1} \mathrm{~s}^{-2}$ ), vertical circulation (vector), and ascent (shaded: $\geq 0.5 \times$ $10^{-1} \mathrm{~m} \mathrm{~s}^{-1}$ ). The TC center is indicated by the red triangle.

underlying surface, topography, lower-level monsoon trough, and two upper-level midlatitude trough-jet systems. When Oswald was located at lower latitudes, the active monsoon trough provided favorable low-level vorticity to contribute to the maintenance of Oswald's remnants and sufficient environmental moisture to contribute to the heavy rainfall. As Oswald moved poleward, the two consecutive midlatitude troughs further contributed to the maintenance of Oswald's circulation over land and the prolonged rainfall. These different environmental systems at different periods of Oswald's over land movement contributed to the longevity of Oswald's circulation and the production of the unusual and widespread heavy rainfall.

Specifically, the first rainfall (I) over Cape York Peninsula had a preferred rainfall location in the downshear sector, which may have been contributed to 
(a)

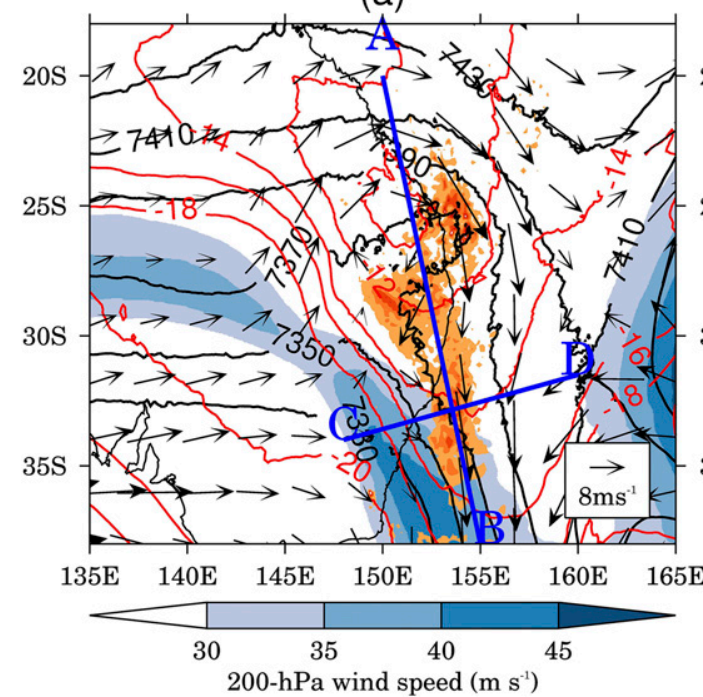

(c)

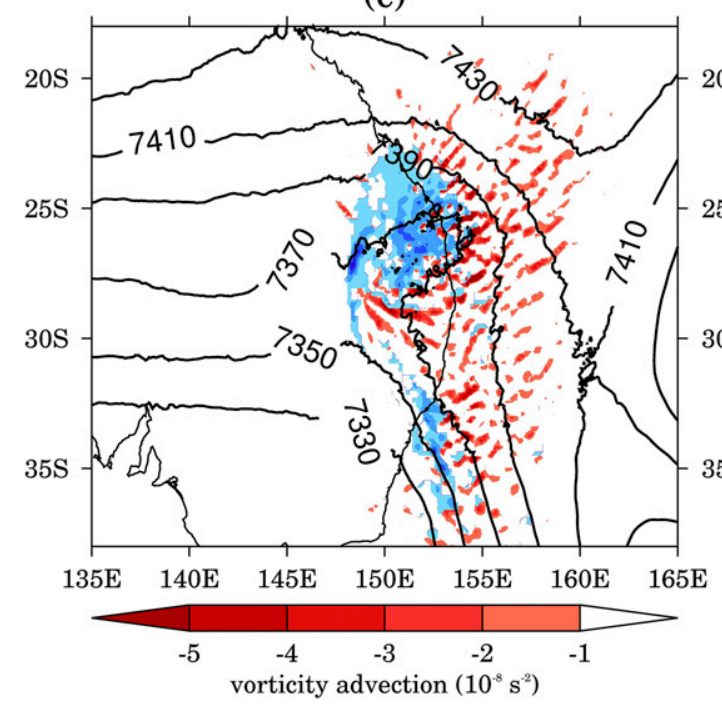

(b)

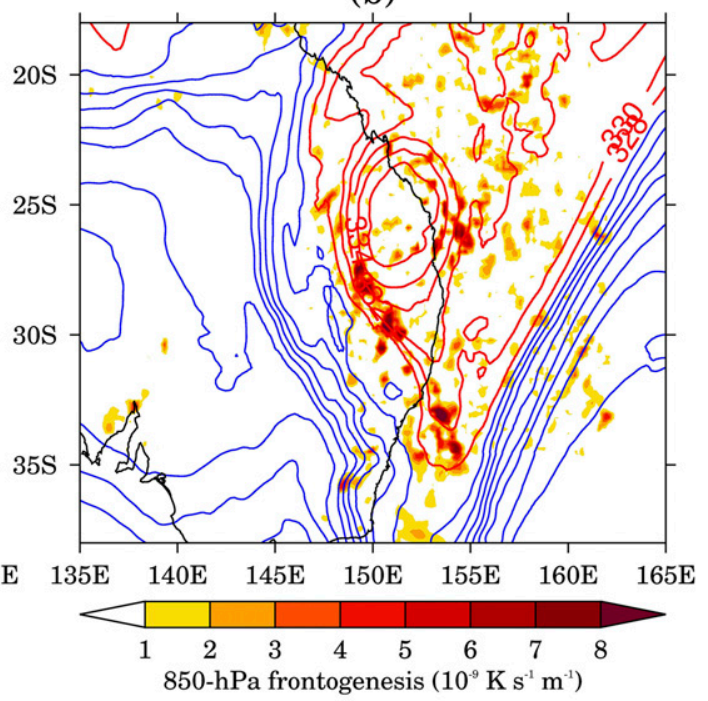

(d)

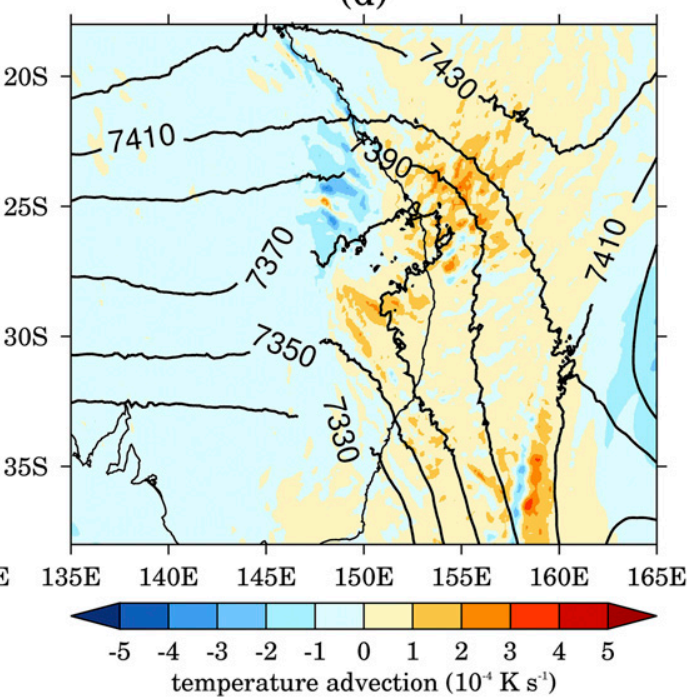

FIG. 13. As in Fig. 11, but the time is averaged from 0000 UTC 27 Jan to 0000 UTC 28 Jan 2013 during the second TC-trough interaction.

by the weak environmental VWS. However, the local maximum rain centers near the coast can be attributed mainly to enhanced boundary layer convergence due to increased friction at the land-sea boundary, which is supported by the sensitivity simulations. In TER a similar double maxima developed near the land-sea boundary, whereas the rain in OCEAN is considerably reduced and located well away from where the coast should lie. The moisture in the active monsoon trough likely contributed to the heavy rainfall. The CTL and TER simulations demonstrated that the second rainfall region (II) was a result of the joint effects of boundary layer convergence caused by deceleration of the onshore wind at the land-sea boundary, the lifting caused by local topography, with TC motion-induced frictional convergence providing some modulation of the offshore rainfall. The large-scale moisture in the monsoon trough environment also contribute to the amount of rainfall. In contrast, the third rainfall region (III) near Rockhampton was an elongated, widespread swath, which lasted for about 5 days. This stage was characterized by two consecutive TC-trough interactions. In addition to increasing environmental VWS, the favorable synoptic-scale atmospheric forcing generated by the passage of the two upper-level trough-jet systems (e.g., differential cyclonic vorticity advection or PV ejection, warm advection, and associated $\mathbf{Q}$-vector convergence) and mesoscale frontogenesis lifting are the 
(a)

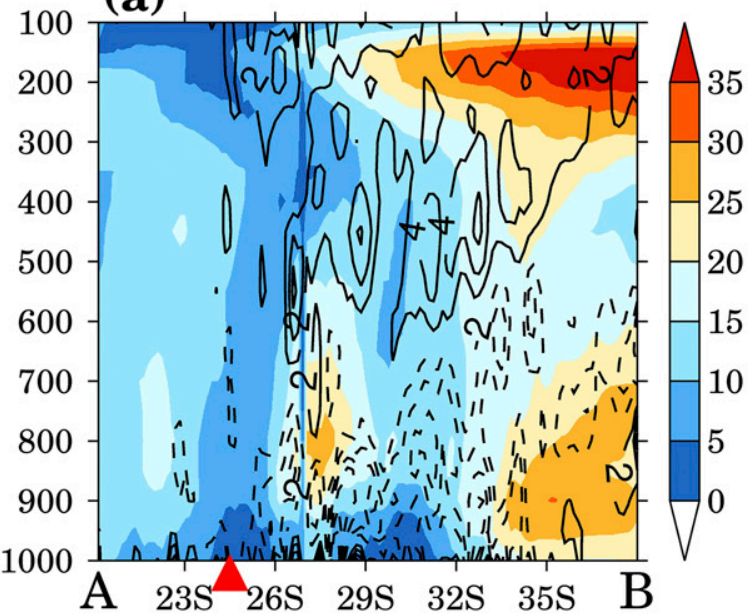

(c)

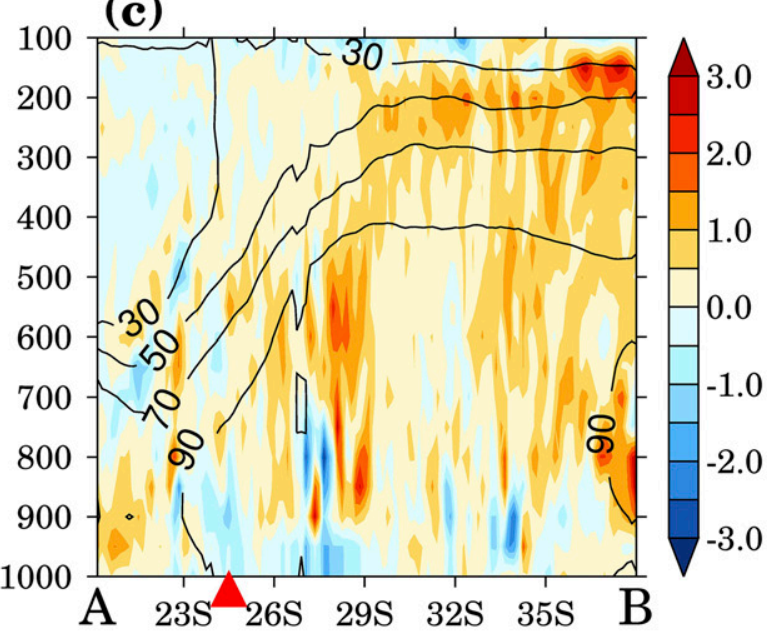

(e)

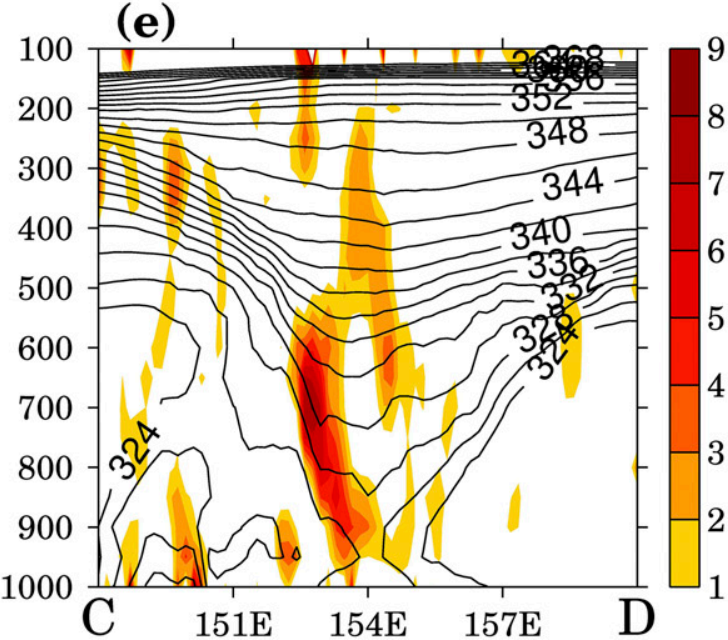

(b)
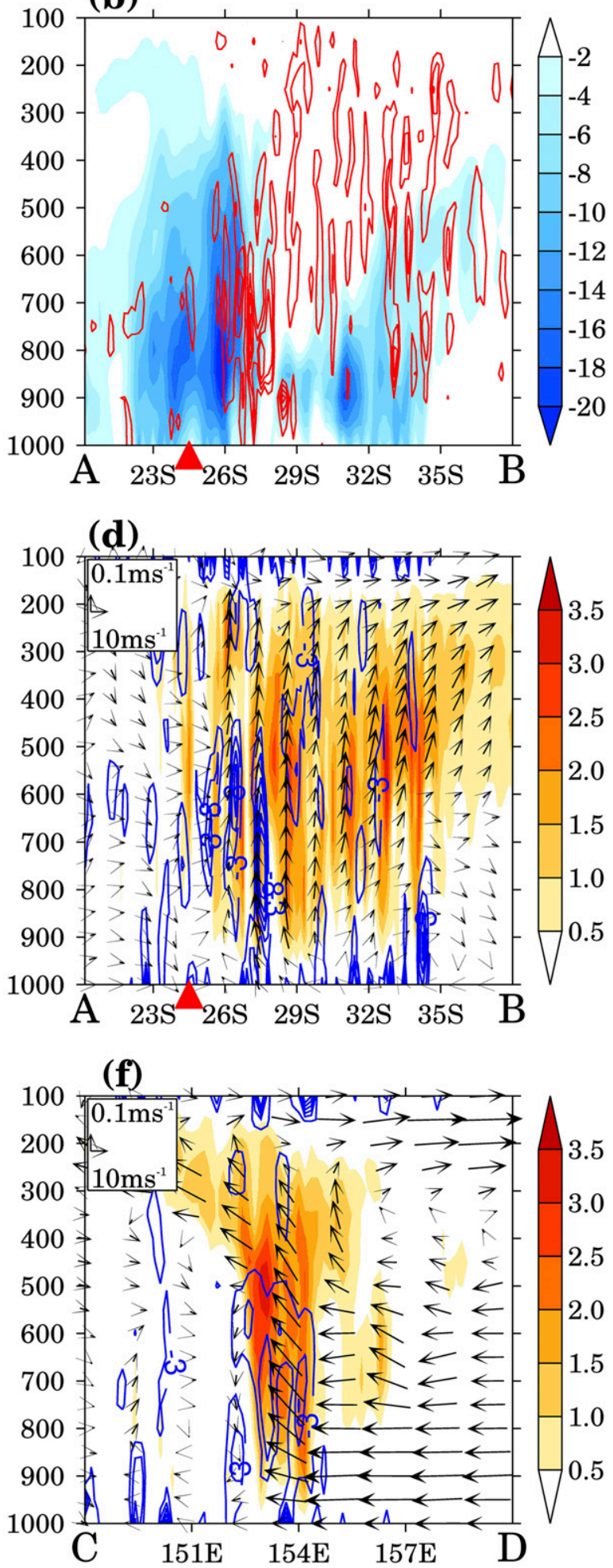

FIG. 14. (a)-(d) Same as Fig. 12; (e) equivalent potential temperature (black contour, intervals: $2 \mathrm{~K}$ ) and frontogenesis function (red shaded: $\geq 1 \times 10^{-9} \mathrm{~K} \mathrm{~s}^{-1} \mathrm{~m}^{-1}$ ); and (f) $\mathbf{Q}$-vector divergence (blue contours: $\leq-3 \times 10^{-11} \mathrm{~J} \mathrm{~kg}^{-1} \mathrm{~m}^{-1} \mathrm{~s}^{-2}$ ), vertical circulation (vector), and ascent (shaded: $\geq 0.5 \times 10^{-1} \mathrm{~m} \mathrm{~s}^{-1}$ ) along the line C-D in Fig. 13a, and the time is averaged from 0000 UTC 27 Jan to 0000 UTC 28 Jan 2013. 
major reasons for the development of asymmetric convection in the TC southeast quadrant and the large linear rainband. The similar primary elongated rain swaths in both TER and OCEAN further support the thesis that the trough-TC interaction provided a major source of precipitation for this region though some subtle differences still exist in these sensitivity experiments, for example, the rainfall in OCEAN was located farther offshore and weaker probably influenced by the shorter duration and lack of underlying land-sea contrast and topography.

Although this paper focused on the rainfall mechanisms as an important component of explaining the high impacts of this relatively weak TC, there are remaining important questions about how TC Oswald continued to exist for so many days while tracking over land. Thus, future work will include a detailed analysis of the changes in TC Oswald's intensity and structure to understand the longevity of this system. In addition, a detailed analysis of how TC Oswald responded to the southwest PV injection from the two consecutive troughs will be investigated.

Acknowledgments. This research was undertaken with the assistance of resources and services from the National Computational Infrastructure (NCI), which is supported by the Australian government. We thank the three anonymous reviewers for their comments, which have considerably improved the original manuscript.

\section{REFERENCES}

Atallah, E. H., L. F. Bosart, and A. R. Aiyyer, 2007: Precipitation distribution associated with landfalling tropical cyclones over the eastern United States. Mon. Wea. Rev., 135, 2185-2206, https://doi.org/10.1175/MWR3382.1.

Bao, X. W., and Coauthors, 2015: Diagnostics for an extreme rain event near Shanghai during the landfall of Typhoon Fitow (2013). Mon. Wea. Rev., 143, 3377-3405, https://doi.org/ 10.1175/MWR-D-14-00241.1.

Braun, S. A., M. T. Montgomery, and Z. Pu, 2006: High-resolution simulation of Hurricane Bonnie (1998). Part I: The organization of eyewall vertical motion. J. Atmos. Sci., 63, 19-42, https://doi.org/10.1175/JAS3598.1.

Bureau of Meteorology, 2013: Special climate statement 44-Extreme rainfall and flooding in coastal Queensland and New South Wales. Bureau of Meteorology, 18 pp., http://www.bom.gov.au/climate/current/statements/scs44.pdf.

Chen, L., 2012: Forecasting and Disasters of Typhoons (in Chinese). China Meteorological Press, $370 \mathrm{pp}$.

Chen, S. S., J. A. Knaff, and F. D. Marks, 2006: Effects of vertical wind shear and storm motion on tropical cyclone rainfall asymmetries deduced from TRMM. Mon. Wea. Rev., 134, 3190-3208, https://doi.org/10.1175/MWR3245.1.

Corbosiero, K. L., and J. Molinari, 2002: The effects of vertical wind shear on the distribution of convection in tropical cyclones. Mon. Wea. Rev., 130, 2110-2123, https://doi.org/ 10.1175/1520-0493(2002)130<2110:TEOVWS > 2.0.CO;2.
- and - 2003: The relationship between storm motion, vertical wind shear, and convective asymmetries in tropical cyclones. J. Atmos. Sci., 60, 366-376, https://doi.org/10.1175/ 1520-0469(2003)060<0366:TRBSMV $>2.0 . \mathrm{CO} ; 2$.

Davidson, N. E., and S. K. Kar, 2002: Upper-tropospheric flow transitions during rapid tropical cyclone intensification. Quart. J. Roy. Meteor. Soc., 128, 861-891, https://doi.org/10.1256/ 0035900021643728.

DeHart, J. C., and R. A. Houze Jr., 2017: Orographic modification of precipitation processes in Hurricane Karl (2010). Mon. Wea. Rev., 145, 4171-4186, https://doi.org/10.1175/MWR-D17-0014.1.

_ - — , and R. F. Rogers, 2014: Quadrant distribution of tropical cyclone inner-core kinematics in relation to environmental shear. J. Atmos. Sci., 71, 2713-2732, https://doi.org/ 10.1175/JAS-D-13-0298.1.

DeMaria, M., J. Kaplan, and J. J. Baik, 1993: Upper-level eddy angular momentum fluxes and tropical cyclone intensity change. J. Atmos. Sci., 50,1133-1147, https://doi.org/10.1175/ 1520-0469(1993)050<1133:ULEAMF $>2.0$. CO;2.

Deng, A., and D. R. Stauffer, 2006: On improving 4-km mesoscale model simulations. J. Appl. Meteor. Climatol., 45, 361-381, https://doi.org/10.1175/JAM2341.1.

—_, N. L. Seaman, G. K. Hunter, and D. R. Stauffer, 2004: Evaluation of interregional transport using the MM5SCIPUFF system. J. Appl. Meteor., 43, 1864-1886, https:// doi.org/10.1175/JAM2178.1.

Deng, D., and E. A. Ritchie, 2018: Rainfall characteristics of recurving tropical cyclones over the western North Pacific. J. Climate, 31, 575-592, https://doi.org/10.1175/JCLI-D-170415.1.

— N. E. Davidson, L. Hu, K. J. Tory, M. C. N. Hankinson, and S. Gao, 2017: Potential vorticity perspective of vortex structure changes of tropical cyclone Bilis (2006) during a heavy rain event following landfall. Mon. Wea. Rev., 145, 1875-1895, https://doi.org/10.1175/MWR-D-16-0276.1.

Didlake, A. C., Jr., and M. R. Kumjian, 2017: Examining polarimetric radar observations of bulk microphysical structures and their relation to vortex kinematics in Hurricane Arthur (2014). Mon. Wea. Rev., 145, 4521-4541, https://doi.org/ 10.1175/MWR-D-17-0035.1.

Fischer, M. S., B. H. T. Tang, and K. L. Corbosiero, 2017: Assessing the influence of upper-tropospheric troughs on tropical cyclone intensification rates after genesis. Mon. Wea. Rev., 145, 1295-1313, https://doi.org/10.1175/MWR-D-16-0275.1.

Frank, W. M., and E. A. Ritchie, 1999: Effects of environmental flow upon tropical cyclone structure. Mon. Wea. Rev., 127, 2044-2061, https://doi.org/10.1175/1520-0493(1999)127<2044: EOEFUT $>2.0 . \mathrm{CO} ; 2$.

_, and _ 2001: Effects of vertical wind shear on the intensity and structure of numerically simulated hurricanes. Mon. Wea. Rev., 129, 2249-2269, https://doi.org/10.1175/1520-0493(2001) $129<2249$ :EOVWSO $>2.0 . \mathrm{CO} ; 2$.

Glisan, J. M., W. J. Gutowski Jr., J. J. Cassano, and M. E. Higgins, 2013: Effects of spectral nudging in WRF on Arctic temperature and precipitation simulations. J. Climate, 26, 3985-3999, https://doi.org/10.1175/JCLI-D-12-00318.1.

Halverson, J., G. M. Heymsfield, J. Simpson, H. Pierce, T. Hock, and E. A. Ritchie, 2006: Warm core structure of Hurricane Erin diagnosed from high altitude dropsondes during CAMEX-4. J. Atmos. Sci., 63, 309-324, https://doi.org/10.1175/JAS3596.1.

Hanley, D., J. Molinari, and D. Keyser, 2001: A composite study of the interactions between tropical cyclones and upper-tropospheric 
troughs. Mon. Wea. Rev., 129, 2570-2584, https://doi.org/10.1175/ 1520-0493(2001)129<2570:ACSOTI >2.0.CO;2.

Hence, D. A., and R. A. Houze Jr., 2011: Vertical structure of hurricane eyewalls as seen by the TRMM Precipitation Radar. J. Atmos. Sci., 68, 1637-1652, https://doi.org/10.1175/ 2011JAS3578.1.

Hong, S. Y., J. Dudhia, and S. H. Chen, 2004: A revised approach to ice microphysical processes for the bulk parameterization of clouds and precipitation. Mon. Wea. Rev., 132, 103-120, https://doi.org/10.1175/1520-0493(2004)132<0103:ARATIM> 2.0.CO;2.

_- Y. Noh, and J. Dudhia, 2006: A new vertical diffusion package with an explicit treatment of entrainment processes. Mon. Wea. Rev., 134, 2318-2341, https://doi.org/10.1175/MWR3199.1.

Jones, S., 1995: The evolution of vortices in vertical shear. I: Initially barotropic vortices. Quart. J. Roy. Meteor. Soc., 121, 821-851, https://doi.org/10.1002/qj.49712152406.

Kain, J. S., 2004: The Kain-Fritsch convective parameterization: An update. J. Appl. Meteor., 43, 170-181, https://doi.org/ 10.1175/1520-0450(2004)043<0170:TKCPAU > 2.0.CO;2.

Kaplan, J., and M. DeMaria, 2003: Large-scale characteristics of rapidly intensifying tropical cyclones in the North Atlantic basin. Wea. Forecasting, 18, 1093-1108, https://doi.org/ 10.1175/1520-0434(2003)018<1093:LCORIT>2.0.CO;2.

Klein, P. M., P. A. Harr, and R. L. Elsberry, 2000: Extratropical transition of western North Pacific tropical cyclones: An overview and conceptual model of the transformation stage. Wea. Forecasting, 15, 373-395, https://doi.org/10.1175/15200434(2000)015<0373:ETOWNP>2.0.CO;2.

Leroux, M.-D., M. Plu, D. Barbary, F. Roux, and P. Arbogast, 2013: Dynamical and physical processes leading to tropical cyclone intensification under upper-level trough forcing. J. Atmos. Sci., 70, 2547-2565, https://doi.org/10.1175/JAS-D-12-0293.1.

Li, Y., K. K. W. Cheung, and J. C. L. Chan, 2014: Numerical study on the development of asymmetric convection and vertical wind shear during tropical cyclone landfall. Quart. J. Roy. Meteor. Soc., 140, 1866-1877, https:// doi.org/10.1002/qj.2259.

Lin, Y. L., S. Chiao, T.-A. Wang, M. L. Kaplan, and R. P. Weglarz, 2001: Some common ingredients for heavy orographic rainfall. Wea. Forecasting, 16, 633-660, https://doi.org/10.1175/15200434(2001)016<0633:SCIFHO > 2.0.CO;2.

Lonfat, M., F. M. Marks, and S. Y. Chen, 2004: Precipitation distribution in tropical cyclones using the Tropical Rainfall Measuring Mission (TRMM) microwave imager: A global perspective. Mon. Wea. Rev., 132, 1645-1660, https://doi.org/ 10.1175/1520-0493(2004)132<1645:PDITCU>2.0.CO;2.

McTaggart-Cowan, R., T. J. Galarneau, L. F. Bosart, R. W. Moore, and O. Martius, 2013: A global climatology of baroclinically influenced tropical cyclogenesis. Mon. Wea. Rev., 141, 1963 1989, https://doi.org/10.1175/MWR-D-12-00186.1.

Miller, B., 1958: Rainfall rates in Florida hurricanes. Mon. Wea. Rev., 86, 258-264, https://doi.org/10.1175/1520-0493(1958) 086<0258:RRIFH>2.0.CO;2.

Milrad, S. M., E. H. Atallah, and J. R. Gyakum, 2013: Precipitation modulation by the Saint Lawrence River valley in association with transitioning tropical cyclones. Wea. Forecasting, 28, 331352, https://doi.org/10.1175/WAF-D-12-00071.1.

Misumi, R., 1996: A study of the heavy rainfall over the Ohsumi Peninsula (Japan) caused by Typhoon 9307. J. Meteor. Soc. Japan, 74, 101-113, https://doi.org/10.2151/jmsj1965.74.1_101.

Mlawer, E. J., S. J. Taubman, P. D. Brown, M. J. Iacono, and S. A. Clough, 1997: Radiative transfer for inhomogeneous atmospheres: RRTM, a validated correlated-k model for the longwave. J. Geophys. Res., 102, $16663-16682$, https:// doi.org/10.1029/97JD00237.

Molinari, J., and D. Vollaro, 1989: External influences on hurricane intensity. Part I: Outflow layer eddy angular momentum fluxes. J. Atmos. Sci., 46, 1093-1105, https://doi.org/10.1175/ 1520-0469(1989)046<1093:EIOHIP>2.0.CO;2.

$\longrightarrow$, and -1990 : External influences on hurricane intensity. Part II: Vertical structure and response of the hurricane vortex. J. Atmos. Sci., 47, 1902-1918, https://doi.org/10.1175/15200469(1990)047<1902:EIOHIP>2.0.CO;2.

Moore, B. J., L. F. Bosart, D. Keyser, and M. L. Jurewicz, 2013: Synoptic-scale environments of predecessor rain events occurring east of the Rocky Mountains in association with Atlantic basin tropical cyclones. Mon. Wea. Rev., 141, 10221047, https://doi.org/10.1175/MWR-D-12-00178.1.

Otte, T. L., C. G. Nolte, M. J. Otte, and J. H. Bowden, 2012: Does nudging squelch the extremes in regional climate modeling? J. Climate, 25, 7046-7066, https://doi.org/10.1175/JCLI-D-1200048.1.

Peirano, C. M., K. L. Corbosiero, and B. H. Tang, 2016: Revisiting trough interactions and tropical cyclone intensity change. Geophys. Res. Lett., 43, 5509-5515, https://doi.org/10.1002/ 2016 GL069040.

Rappaport, E. N., 2000: Loss of life in the United States associated with recent Atlantic tropical cyclones. Bull. Amer. Meteor. Soc., 81, 2065-2074, https://doi.org/10.1175/1520-0477(2000) $081<2065$ :LOLITU $>2.3$.CO;2.

Reasor, P. D., R. F. Rogers, and S. Lorsolo, 2013: Environmental flow impacts on tropical cyclone structure diagnosed from airborne Doppler radar composites. Mon. Wea. Rev., 141, 2949-2969, https://doi.org/10.1175/MWR-D-12-00334.1.

Riemer, M., and F. Laliberté, 2015: Secondary circulation of tropical cyclones in vertical wind shear: Lagrangian diagnostic and pathways of environmental interaction. J. Atmos. Sci., 72 , 3517-3536, https://doi.org/10.1175/JAS-D-14-0350.1.

Ritchie, E. A., and R. L. Elsberry, 2001: Simulations of the transformation stage of the extratropical transition of tropical cyclones. Mon. Wea. Rev., 129, 1462-1480, https://doi.org/10.1175/ 1520-0493(2001)129<1462:SOTTSO > 2.0.CO;2.

$\ldots$ - and _ 2003: Simulations of the extratropical transition of tropical cyclones: Contributions by the midlatitude upper-level trough to reintensification. Mon. Wea. Rev., 131, 2112-2128, https://doi.org/10.1175/1520-0493(2003) $131<2112$ :SOTETO $>2.0$. CO 2 .

Rogers, R., S. Chen, J. Tenerelli, and H. Willoughby, 2003: Numerical study of the impact of vertical shear on the distribution of rainfall in Hurricane Bonnie (1998). Mon. Wea. Rev., 131, 1577-1599, https://doi.org/10.1175//2546.1.

Rotunno, R., and R. Ferretti, 2001: Mechanisms of intense Alpine rainfall. J. Atmos. Sci., 58, 1732-1749, https://doi.org/10.1175/ 1520-0469(2001)058<1732:MOIAR > 2.0.CO;2.

$\longrightarrow$, and - 2003: Orographic effects on rainfall in MAP cases IOP 2b and IOP 8. Quart. J. Roy. Meteor. Soc., 129, 373-390, https://doi.org/10.1256/qj.02.20.

Shapiro, L. J., 1983: The asymmetric boundary layer flow under a translating hurricane. J. Atmos. Sci., 40, 1984-1998, https://doi.org/10.1175/1520-0469(1983)040<1984:TABLFU> 2.0.CO;2.

Simpson, J., E. Ritchie, G. J. Holland, J. Halverson, and S. Stewart, 1997: Mesoscale interactions in tropical cyclone genesis. Mon. Wea. Rev., 125, 2643-2661, https://doi.org/ 10.1175/1520-0493(1997)125<2643:MIITCG > 2.0.CO;2. 
Skamarock, W. C., and Coauthors, 2008: A description of the Advanced Research WRF version 3. NCAR Tech. Note NCAR/TN475+STR, 113 pp., https://doi.org/10.5065/D68S4MVH.

Smith, R. B., P. Schafer, D. J. Kirshbaum, and E. Regina, 2009a: Orographic precipitation in the tropics: Experiments in Dominica. J. Atmos. Sci., 66, 1698-1716, https://doi.org/ 10.1175/2008JAS2920.1.

__, _—, D. Kirshbaum, and E. Regina, 2009b: Orographic enhancement of precipitation inside Hurricane Dean.

J. Hydrometeor., 10, 820-831, https://doi.org/10.1175/ 2008JHM1057.1.

Stovern, D. R., and E. A. Ritchie, 2016: Simulated sensitivity of tropical cyclone size and structure to the atmospheric temperature profile. J. Atmos. Sci., 73, 4553-4571, https://doi.org/ 10.1175/JAS-D-15-0186.1.

Wang, Y., 2009: How do outer spiral rainbands affect tropical cyclone structure and intensity? J. Atmos. Sci., 66, 1250-1273, https://doi.org/10.1175/2008JAS2737.1.
Y. Wang, and H. Fudeyasu, 2009: The role of Typhoon Songda (2004) in producing distantly located heavy rainfall in Japan. Mon. Wea. Rev., 137, 3699-3716, https://doi.org/ 10.1175/2009MWR2933.1.

Wang, Z., T. J. Dunkerton, and M. T. Montgomery, 2012: Application of the marsupial paradigm to tropical cyclone formation from northwestward-propagating disturbances. Mon. Wea. Rev., 140, 66-76, https://doi.org/10.1175/ 2011MWR3604.1.

Wu, C. C., T. H. Yen, Y. H. Kuo, and W. Wang, 2002: Rainfall simulation associated with Typhoon Herb (1996) near Taiwan. Part I: The topographic effect. Wea. Forecasting, 17, 1001-1015, https://doi.org/10.1175/1520-0434(2003)017<1001: RSAWTH $>2.0$. CO; 2 .

Yu, C.-K., and L.-W. Cheng, 2008: Radar observations of intense orographic precipitation associated with Typhoon Xangsane (2000). Wea. Forecasting, 136, 497-521, https:// doi.org/10.1175/2007MWR2129.1. 